\title{
Text representations as reflected in patterns of cognitive distance
}

\author{
STEPHEN DOPKINS \\ George Washington University, Washington, D.C.
}

\begin{abstract}
Subjects performed a task that involved learning a text and then indicating, for each of a series of pairs of words, whether they belonged to the same sentence of that text. When the principle of argument overlap or causal coherence was the sole integrative factor in a text, negative response times and error rates reflected distances in the network representation predicted by the principle. When the two principles predicted conflicting representations for a text, response times and error rates reflected the predictions of the principle of argument overlap. The results were interpreted as suggesting that network connections predicted by the two principles are both present in the memory representations of texts and that causal connections are recorded at a more abstract level of representation than are argument overlap connections.
\end{abstract}

It is commonly assumed that the memory representations of texts have the properties of networks (Graesser, 1981; O'Brien \& Myers, 1987). Specifically, it is assumed that a text's mental representation consists of a set of primitive elements or nodes (usually these are assumed to record basic idea units such as propositions) integrated with pairwise links.

There has been disagreement about the principles that determine the links in the network representations for texts, with two distinct candidate principles each receiving substantial attention. Although these principles have been formulated differently by different writers, it will be sufficient for the purposes of the present work to characterize them roughly, extracting what is common to the different formulations. According to the argument overlap hypothesis (Anderson, 1976, 1983; Kintsch \& van Dijk, 1978; van Dijk \& Kintsch, 1983), two nodes in a text network representation are linked if they record idea units that contain the same propositional argument. According to the causal coherence hypothesis (Fletcher \& Bloom, 1988; Graesser, 1981; Trabasso \& Sperry, 1985; Trabasso $\&$ van den Broek, 1985), two nodes in a text network representation are linked if one of them records an event that is the immediate causal precondition for the event recorded in the other one.

Various methods have been used in the past to gather support for the argument overlap and causal coherence hypotheses. Some of the most convincing support for both hypotheses has been obtained with speeded response tasks. Probe recognition tasks have been used to show that anaphoric inferences are drawn during the process-

The author is grateful to Jerry Myers and Johanna Nordlie for helpful comments on earlier versions of this paper, and to Tom Bever, Barbara Dosher, and David Krantz for useful suggestions concerning the research that it reports. Correspondence should be addressed to S. Dopkins, Psychology Department, George Washington University, 2125 G Street, N.W., Washington, DC 20052 (e-mail: dopkins@ gwuvm.gwu.edu). ing of texts, as the argument overlap hypothesis predicts (Dell, McKoon, \& Ratcliff, 1983; O'Brien, Duffy, \& Myers, 1986). Priming tasks have been used to show that texts are represented in memory according to the predictions of this hypothesis. In one key study, subjects read texts and indicated, for sequences of words, whether or not each word occurred in one of the texts (McKoon \& Ratcliff, 1980). Priming effects in the data for the recognition test reflected distances in networks predicted by the argument overlap hypothesis.

Speeded response tasks have also been used to gather support for the causal coherence hypothesis. Probe recognition and lexical decision tasks have been used to show that causal inferences are drawn during the processing of texts (Bloom, Fletcher, van den Broek, Reitz, \& Shapiro, 1990; Dopkins, Klin, \& Myers, 1993; Magliano, Baggett, Johnson, \& Graesser, 1993; Trabasso \& Suh, 1993). Priming tasks have been used to show that causal connections are preserved in the memory representations of texts (van den Broek \& Lorch, 1993).

The present study attempted to find support for the argument overlap and causal coherence hypotheses using a new speeded response task. The strategy, as in the work of McKoon and Ratcliff (1980), focused on distance effects that reflected the predictions of the two hypotheses. The study advanced previous work in that a new method was introduced for producing distance effects.

The results obtained with this method should usefully reinforce earlier findings. This is particularly important with respect to the findings of McKoon and Ratcliff (1980). These findings constitute one of the key pieces of support for the argument overlap hypothesis. Yet no attempt was made to control for the predictions of the causal coherence hypothesis in the texts for the study. (At the time that the study was conducted, the causal coherence hypothesis had not yet been formulated.)

More generally, this new method should usefully complement the priming method as a means of producing dis- 
tance effects that reflect network representations. A recent view of priming (Ratcliff \& McKoon, 1988) suggests that priming may not be particularly effective for producing such results. This issue will be taken up in the General Discussion section.

The present method is based on the sentence membership (SM) task. During the exposure phase of this task, the subject processes a text, either memorizing it to a strict criterion (Experiments 1-6) or reading it in a more natural manner (Experiments 7 and 8). During the test phase, the subject indicates, for each of a series of pairs of words, whether or not they belong to the same sentence of that text. In analyzing the data from this task, the negative trials are of greatest interest because a distance effect is observed; response time (RT) and error rate decrease with increases in the cognitive distance between the test words in the memory representation of the text.

The purpose of the study was to use the SM distance effect to gather support for the argument overlap and causal coherence hypotheses. Experiments were conducted to test predictions that were generated in a twostep procedure: (1) artificial texts were constructed for which the two hypotheses predicted particular network representations, and (2) particular patterns of negative SM performance were predicted on the basis of these network representations.

Whereas the first step in this prediction procedure was straightforward, the second was more complex. In order to predict patterns of SM performance on the basis of network representations, it was necessary to specify the process whereby information about the relative position of words in a network representation is translated into negative SM RT and error rate. Two hypothetical processes were considered.

According to the network connection hypothesis, negative SM RT and error rate decrease with decreases in the degree of network connection between the network nodes in which the probe words are recorded. According to the location code hypothesis, negative SM RT and error rate decrease with increases in the difference between codes that are accessed with the probe words and give their locations in the network representation of the text. An attempt was made in the initial phase of the study to choose between these two hypotheses.

In summary, the study tested two sets of hypotheses. The primary focus was on two representation hypotheses: the argument overlap and causal coherence hypotheses. In order to test these hypotheses, it was also necessary to test two process hypotheses: the network connection and location code hypotheses.

The general organization of the study was as follows. The first three experiments laid the foundation for the project. Experiment 1 demonstrated the basic distance effect. Experiment 2 attempted to choose between the two process hypotheses. Experiment 3 attempted to show that negative SM performance varies with distance in a text's network representation rather than with distance in the text's surface form.
The rest of the experiments used the SM task to gather evidence for the argument overlap and causal coherence hypotheses. Experiment 4 used two texts, in each of which one of the hypotheses was present as the sole integrating factor. The point was to show that the networks predicted by both hypotheses were reflected in SM performance. Experiments 5 and 6 pitted the two hypotheses against one another using texts for which the two hypotheses predicted different network representations. The point of each experiment was to find out which hypothesis best accounted for SM performance. Experiments 7 and 8 replicated the results of Experiments 5 and 6 with more elaborate texts.

\section{EXPERIMENT 1}

Experiment 1 was conducted to demonstrate that performance on negative SM trials depends on cognitive distance. The stimulus material was the text shown in Table 1. The argument overlap and causal coherence hypotheses both predict that this text will be represented in a network with a simple linear structure that parallels its surface form (see Figure 1; the details of the figure will be explained subsequently). Subjects learned this text to a strict criterion and then indicated, for each of a series of pairs of words, whether the two words belonged to the same sentence. RT and error rate for negative trials were analyzed as a function of the difference between the surface positions of the sentences to which the probe words belonged.

Given that the presumed network representation for the text paralleled its surface form, it was reasoned that the cognitive distance between pairs of words from the text would increase as a function of surface position difference regardless of whether cognitive distance was determined by the text's network representation or its surface form. Thus, it was reasoned that an effect of cognitive distance should be expressed as a decrease in negative RT and error rate as a function of surface position difference.

\section{Method}

Subjects. The subjects were 12 students from an introductory psychology class at Columbia College.

Materials. The stimulus text is shown in Table 1. There were 198 negative word-pair probes. They were created by (1) forming all possible unordered pairs of the text's sentences, and (2) choosing, at random, for each of these sentence pairs, three of the four pairs of words that could be formed, in which (a) one of the words was a noun that identified a character, (b) the other word was a verb, and (c) the two words came from different sentences. For pairs of sentences that were adjacent in the text and thus shared a

Table 1

Sample Lines From the Text for Experiment 1

(S1) The millionaire awarded the psychiatrist a grant. (S2) So the psychiatrist trained an assistant. (S3) The assistant analyzed a guru. (S4) And the guru generated a genie. (S5) The genie visited a housewife. (S6) The housewife asked for a gigolo. (S7) But the gigolo offended the neighbors.

Note--S1, S2, .. = Sentence 1, Sentence 2, etc. 


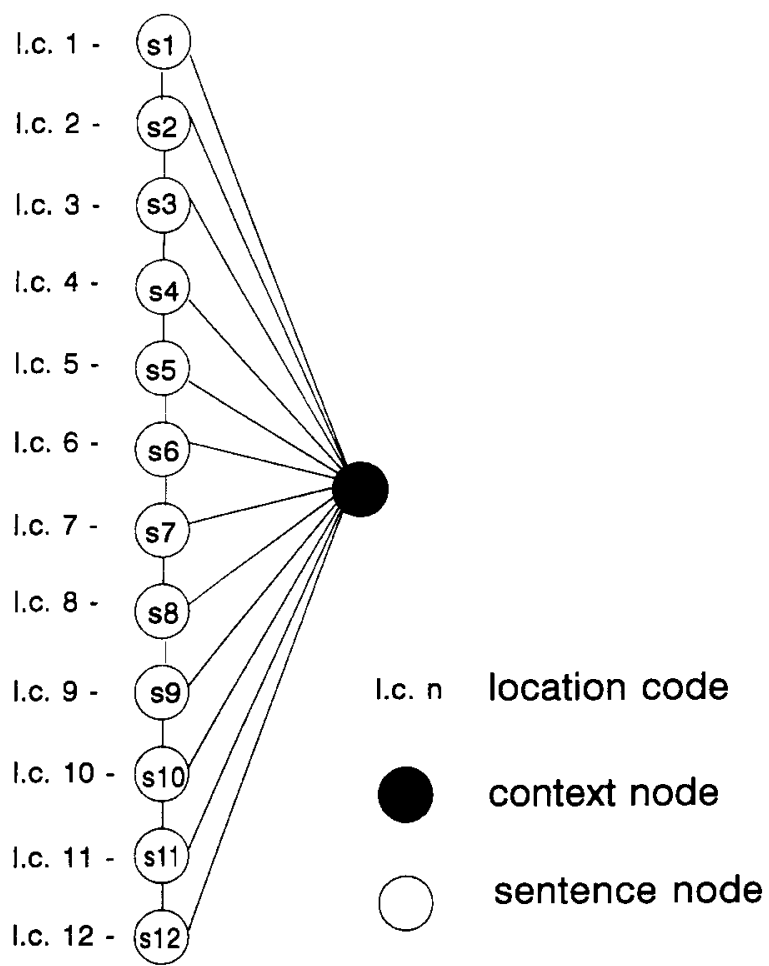

Figure 1. Diagram of the network representation that was assumed for the text of Experiment 1.

common character noun, an added condition was imposed such that this noun was not used. As a result, there were only two possible pairs of words here, one of which was presented twice.

Notice that because all possible pairs of sentences were tested, there were unequal numbers of probes for the different levels of surface position difference. Specifically, there were 33, 30, 27, $24,21,18,15,12,9,6$, and 3 probes for Surface Pcsition Differences $1,2,3,4,5,6,7,8,9,10$, and 11 , respectively.

Notice also that the different surface positions were unequally represented in the probes for the different levels of surface position difference; probes for large values of surface position difference were less likely to contain words from the middle of the text than were probes for small values of surface position difference. Specifically, the probes for Surface Position Differences 1, 2, 3, $4,5,6,7,8,9,10$, and 11 contained words drawn from sentences that were, on the average, $2.27,2.1,2.0,2.0,2.14,2.5,3.0,3.5,4$, 4.5 , and 5 surface positions from the middle of the text.

There were also 216 positive probes. These were obtained as follows: 72 word pairs were constructed by forming all possible ordered pairs of the three content words (character nouns and verbs) in each of the text's 12 sentences. Each of these word pairs was presented three times.

Procedure. The subjects were run one at a time. At the beginning of the session, the subjects were presented with the stimulus text, on a piece of paper, and asked to learn it. They were told that they need not remember the exact wording of the text but should be able to recall its gist and content words.

After studying the text for as long as they wanted, the subjects attempted to reproduce its gist on a piece of paper. If unable to reproduce all 12 of the text's underlying story units, in the proper order, the subjects studied the text some more.

Upon successfully reproducing the gist of the text, the subjects were presented with a series of fill-in-the-blank questions. There were 48 of these questions: 24 tapping memory for the content words in the middle four sentences of the text, 12 tapping memory for the content words in the first four sentences, and 12 tapping memory for the content words in the last four sentences.

The nonuniform distribution of questions was employed in order to forestall the occurrence of a bowed surface position effect in the accessibility of the words in the text. If the words from the middle of the text had been less accessible than the words from the beginning and end, this would have complicated the intended interpretation of the results of the experiment. For example, it was noted above that negative probes for large values of surface position difference were less likely to contain words from the middle of the text than were negative probes for small values of surface position difference. If there had been a bowed accessibility effect, $\mathrm{RT}$ and error rate for negative trials might therefore have decreased as a function of surface position difference simply because the accessibility of the probe words increased as a function of surface position difference. Thus, a decreasing pattern of RT and error rate would not necessarily have reflected an effect of cognitive distance.

On each trial of the test phase, the subjects sisw two words on a microcomputer screen and indicated whether they belonged to the same sentence. The two words in each probe were displayed in the middle of the screen, separated by a distance of 10 character spaces. The subject pressed the right button of a two-button response box to indicate a positive response and pressed the left button to indicate a negative response. The two words then disappeared, and an intertrial interval of $3,500 \mathrm{msec}$ occurred, followed by another trial. The trials were presented in blocks of 69 . The subject was given a chance to take a short break after completing each block of trials.

\section{Results and Discussion}

RT and error rate for the negative trials decreased with increases in surface position difference (see Figure 2). Analyses of variance (ANOVAs) were conducted to test the significance of this pattern. In these and all subsequent ANOVAs, the Greenhouse-Geisser sphericity correction was used. The effect of surface position difference in the RT data was statistically significant $[F(10,110)=$ $\left.5.09, M S_{\mathrm{e}}=56,370, p<.05\right]$. A trend analysis revealed a significant linear component in this effect $[F(1,11)=$ $\left.8.91, M S_{\mathrm{e}}=237,298, p<.01\right]$. The effect in the error rate data was also significant $\left[F(10,110)=5.87, M S_{\mathrm{e}}=\right.$ $0.007, p<.005]$. There was again a significant linear trend $\left[F(1,11)=9.80, M S_{\mathrm{e}}=0.0158, p<.01\right]$.

The data shown in Figure 2 suggest that RT and error rate for negative trials decreased with increases in cognitive distance. There is, however, a less interesting interpretation of these data. As was noted earlier, they might reflect a bowed surface position effect in the accessibility of the words in the probes for the different levels of surface position difference. In order to rule out this interpretation, accessibility estimates were computed for each level of surface position difference.

These estimates were obtained from the data for positive trials. The estimate for a given level of surface position difference was a weighted mean of the means for positive trials involving the different sentences in the text. In this weighted mean, the mean for each sentence was weighted in proportion to the number of times that it was tapped in forming probes for the level of surface position difference in question. Separate analyses were conducted for RT and error rate. 

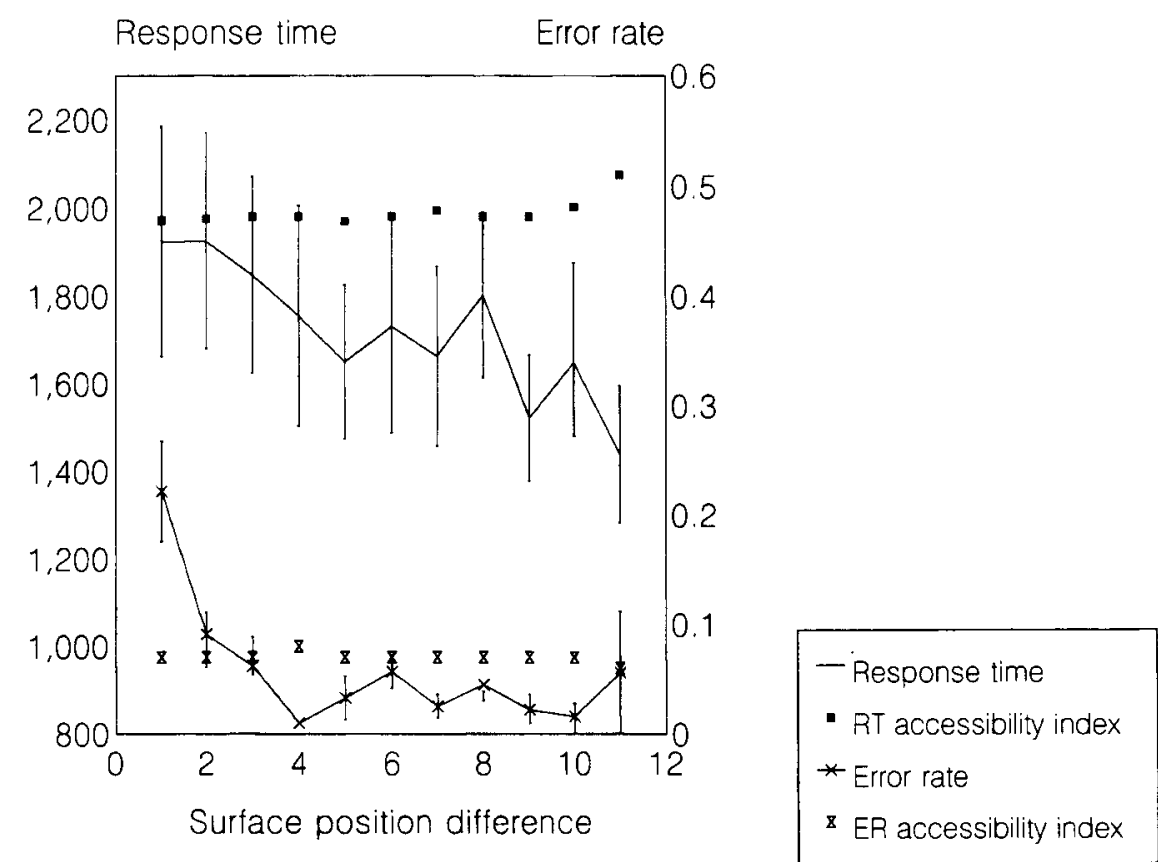

Figure 2. Experiment 1: Performance on negative trials and accessibility indices as a function of surface position difference.

To see the rationale behind this procedure, consider the accessibility estimate for Surface Position Difference 4. Here, the means for positive trials involving Sentences 5-8 were weighted twice as heavily as the means for positive trials involving Sentences 1-4 and 9-12. This was because the probes for Surface Position Difference 4 were drawn from Sentences 1 and 5,2 and 6, 3 and 7, 4 and 8,5 and 9, 6 and 10,7 and 11 , and 8 and 12 . In constructing these probes, Sentences 5-8 were tapped twice as often as Sentences $1-4$ and 9-12.

The RT accessibility index increased slightly with surface position difference (see Figure 2), but this increase was not statistically significant $\left[F(1,11)=2.782, M S_{\mathrm{e}}=\right.$ $16,689, p>.05]$. The error rate accessibility index was constant as a function of surface position difference $(F<1)$. These results suggest that the accessibility of the probe words did not vary, or, if anything, it decreased with surface position difference. This in turn suggests that the results observed on negative trials represent an effect of cognitive distance.

These results suggest that a significant proportion of negative responses in the SM task are emitted because the cognitive distance associated with the probe words is relatively large. A pair of words can evidently be identified more easily as being cognitively distant the more cognitive distance there is between them. It is probably unrealistic to assume that negative SM responses are made solely on the basis of cognitive distance. Other factors are presumably involved. Cognitive distance evidently plays a large enough role, however, that the SM task can be used to test representational hypotheses.
The distance effect observed in Experiment 1 resembles the symbolic distance effect that has been observed in studies of conceptual judgment (Banks, 1977; Kerst \& Howard, 1977; Moyer \& Bayer, 1976). In the latter distance effect, RT to compare pairs of concepts on semantic dimensions increases with the cognitive distance between the concepts. In view of the resemblance between the two distance effects, the data for Experiment 1 were examined more closely for the presence of other patterns that typically co-occur with the symbolic distance effect.

One such pattern is the serial position effect, in which the RT and error rate for comparisons of pairs of concepts that are close on a semantic dimension decrease with increases in the distance of the concepts from the middle of the dimension. A related pattern is the end anchor ef$f e c t$, in which RT and error rate are particularly small for comparisons involving concepts at the ends of the dimension of comparison.

In order to find out whether similar patterns were present in the data for Experiment 1, the data for negative trials on which the probe words came from adjacent sentences were analyzed as a function of surface position. In this analysis, the surface position for a given pair of probe words was the surface position of the pair member that came first in the text. (Note that the question in this analysis is different from the question of whether the accessibility of the items varied with surface position, which was addressed earlier. The issue here is the comparison of the test words rather than their retrieval from memory.)

As Figure 3 shows, there was a modest surface position/ end anchor effect. Responses to probes containing words 


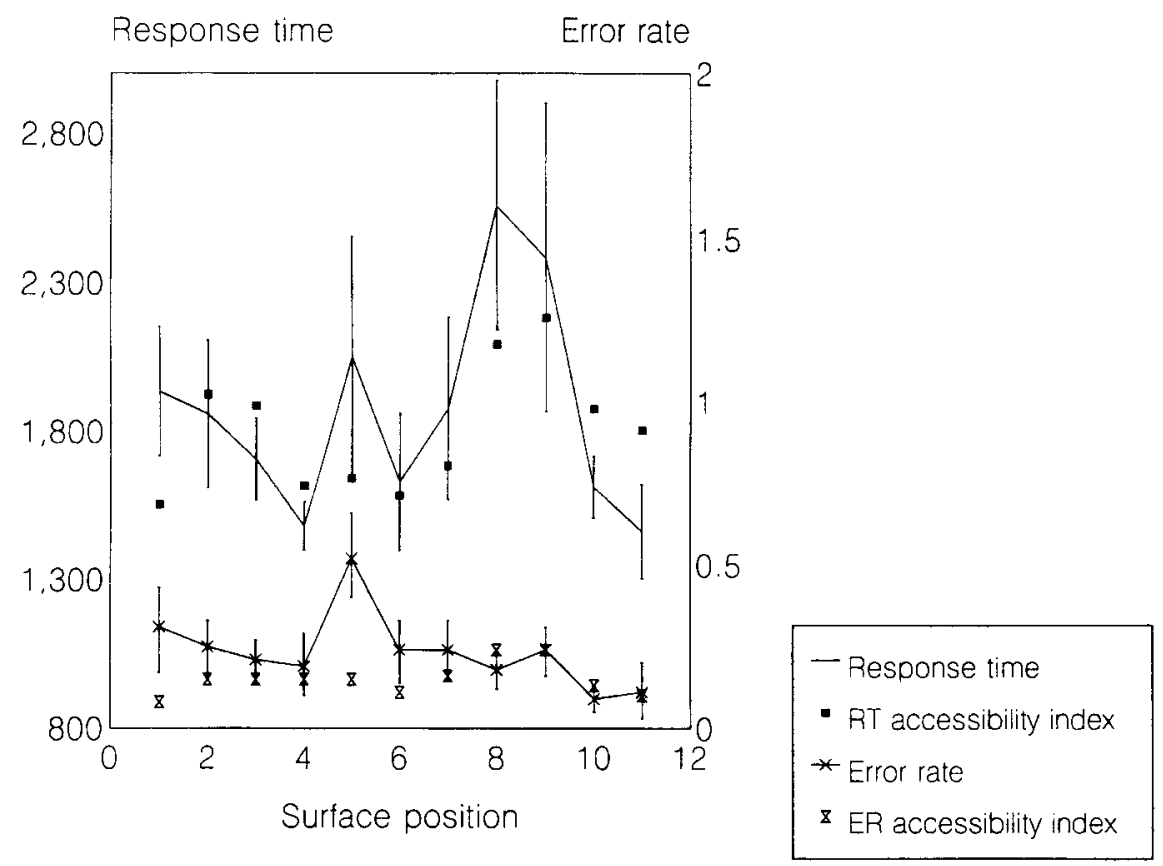

Figure 3. Experiment 1: Performance on negative trials and accessibility indices as a function of surface position.

from the beginning and end of the text tended to be faster and more accurate than responses to probes containing words from the middle of the text. An ANOVA revealed a nearly significant effect of surface position in the RT data $\left[F(10,110)=2.16, M S_{\mathrm{e}}=694,425, p=.11\right]$. A trend analysis revealed a nearly significant quadratic component in this effect $\left[F(1,11)=3.44, M S_{\mathrm{e}}=276,795, p=\right.$ $.09]$. The effect of surface position in the error rate data was also nearly significant $\left[F(10,110)=2.22, M S_{\mathrm{e}}=\right.$ $0.072, p=.08]$, and there was a significant quadratic trend $\left[F(1,11)=2.32, M S_{\mathrm{e}}=0.08, p=.15\right]$. The accessibility indices did not vary with surface position.

These results suggest that the process underlying the SM distance effect may be similar to the process underlying the symbolic distance effect. This has implications for our understanding of the former process, as is discussed later.

The plan in the rest of the study was to use the SM distance effect to gather support for the argument overlap and causal coherence hypotheses. The goal was to produce patterns of SM RT and error rate that reflected networks predicted by the two hypotheses. In order to do this, it was necessary to specify the process whereby information about the relative positions of pairs of words in a network is translated into SM RT and error rate. Experiment 2 was conducted to test two hypotheses concerning this process.

The network connection hypothesis. The network connection hypothesis holds that negative SM RT and error rate decrease with decreases in the degree of network connection between the nodes in which the probe words are recorded. The degree of network connection between the nodes for two words depends in turn on the number of network paths between them and the lengths of these paths. The fewer paths there are between the nodes, and the longer these paths are, the more distantly the nodes are connected.

It may help to instantiate the network connection hypothesis more concretely. This can be done most effectively in terms of the ACT* model of Anderson (1983). According to this model, the availability of information in memory depends on the degree of activation at the network nodes in which it is represented. A network node becomes activated either (1) because it is "turned on" in the processing of perceptual input or the execution of cognitive goals or (2) because activation spreads to it from a node that is turned on. In the latter case, the node becomes more activated the more closely it is connected to the node that is turned on.

The network connection hypothesis could be instantiated in terms of the $\mathrm{ACT}^{*}$ model as follows: When two words are presented as a negative SM probe, the nodes in which they are recorded are turned on. Activation spreads from these nodes into the network in which the rest of the text is represented. The degree of connection between the nodes is inferred from the amount of activation spreading between them. The fewer paths there are between the nodes, and the longer these paths are, the less activation spreads between the nodes and the faster and more accurately the words are identified as belonging to different sentences.

To see how the network connection hypothesis would explain the results of Experiment 1, consider Figure 1, 
which shows a hypothetical network representation of the text for this experiment. It is important to notice several aspects of this representation. (1) Notice that each of the sentences of the text is represented by a node. This disagrees somewhat with prevailing practice in the network representation of verbal material according to which nodes are often used to represent propositions rather than sentences. However, most of the sentences in the texts for the present experiment were little more than single propositions. Thus, the simplification implicit in this network representation can probably be assumed without difficulty. (2) Notice that the sentence nodes are all linked to a common context node. (3) Notice that the sentence nodes are linked in a series as a consequence of the argument overlap and causal coherence relationships between their corresponding sentences.

In the network shown in Figure 1, there are two paths between any pair of sentence nodes: one path that involves visiting the context node and a second path that involves traversing the chain of sentence nodes. The former path is equally long for any pair of sentence nodes. The latter path, in contrast, is longer for pairs of nodes whose sentences are more distant in the text. Thus, degree of network connection decreases with increases in surface position difference. The network connection hypothesis therefore predicts that negative SM RT and error rate will decrease with increases in surface position difference.

The location code hypothesis. The location code hypothesis holds that negative SM RT and error rate decrease with increases in the difference between codes that give the locations of the probe words in the network representation of the text. According to this hypothesis, a code is recorded with each of the idea units of a text that locates it in the network representation of the text. For simplicity, we will assume that the idea units in question are sentences, but they could also be propositions. When a word is presented in an SM probe, the location code for the word's idea unit is accessed. The greater the difference between the location codes accessed with the probe words, the faster and more accurately the words are identified as belonging to different sentences.

For a text such as was used in Experiment 1, whose network representation parallels its surface form, the location code recorded for a given sentence matches its surface position in the text. For more complex texts, this is not the case, as will be seen subsequently.

To see how the location code hypothesis would explain the results of Experiment 1, again consider Figure 1, in which location codes are indicated for all of the sentence nodes. Because the location code for a given sentence matches its surface position, location code difference increases with increases in surface position difference. The location code hypothesis therefore predicts that negative SM RT and error rate will decrease with increases in surface position difference.

The modest surface position effect that was present in the data for Experiment 1 (see Figure 3) provides some support for the location code hypothesis. This surface po- sition effect suggests that the SM distance effect resembles the symbolic distance effect and perhaps should be explained in the same way. Most explanations of the conceptual judgment process that produces the symbolic distance effect posit the comparison of codes that explicitly locate the test items on the dimension of comparison (Banks, 1977; Moyer \& Bayer, 1976). In positing the comparison of explicit location codes, the location code hypothesis resembles these explanations more than the network connection hypothesis does.

\section{EXPERIMENT 2}

Experiment 2 was conducted to choose between the network connection and location code hypotheses. Subjects were tested in a task that was similar in all respects to that of Experiment 1, except that there were two 6sentence texts instead of one 12-sentence text. On the crucial trials during the test phase, the probe words came from different texts. The data for these different-text trials were analyzed as a function of surface position difference. (Notice that whereas this independent variable has the same name as that which was used in Experiment 1 , it has a slightly different meaning. In Experiment 1 , the surface position difference for a pair of words was the difference between the surface positions of their sentences in the text to which they jointly belonged. Here, the surface position difference for a pair of words was the difference between the surface positions of their sentences in the texts to which they respectively belonged.)

The network connection and location code hypotheses make different predictions concerning the results that should be observed on the different-text trials in this experiment. The network connection hypothesis predicts that RT and error rate will be constant as a function of surface position difference, whereas the location code hypothesis predicts that RT and error rate may decrease as a function of surface position difference. The predictions of the two hypotheses will be explained in turn.

\section{Predictions of the Network \\ Connection Hypothesis}

In order to explain the predictions of the network connection hypothesis, it is necessary to specify the network representation for the text pair that was employed in the experiment. Two alternative representations will be considered (see Figure 4). The two representations differ in the way that they integrate the two texts with respect to the experimental context. In Representation A, the nodes for all of the sentences in the two texts are connected to the same context node. In Representation B, the nodes for the sentences in each of the texts are connected to distinct context nodes.

As instantiated in both of these representations, the network connection hypothesis predicts that RT and error rate on different-text trials will be constant as a function of surface position difference. According to the network connection hypothesis, negative SM RT and error 


\section{Representation A}

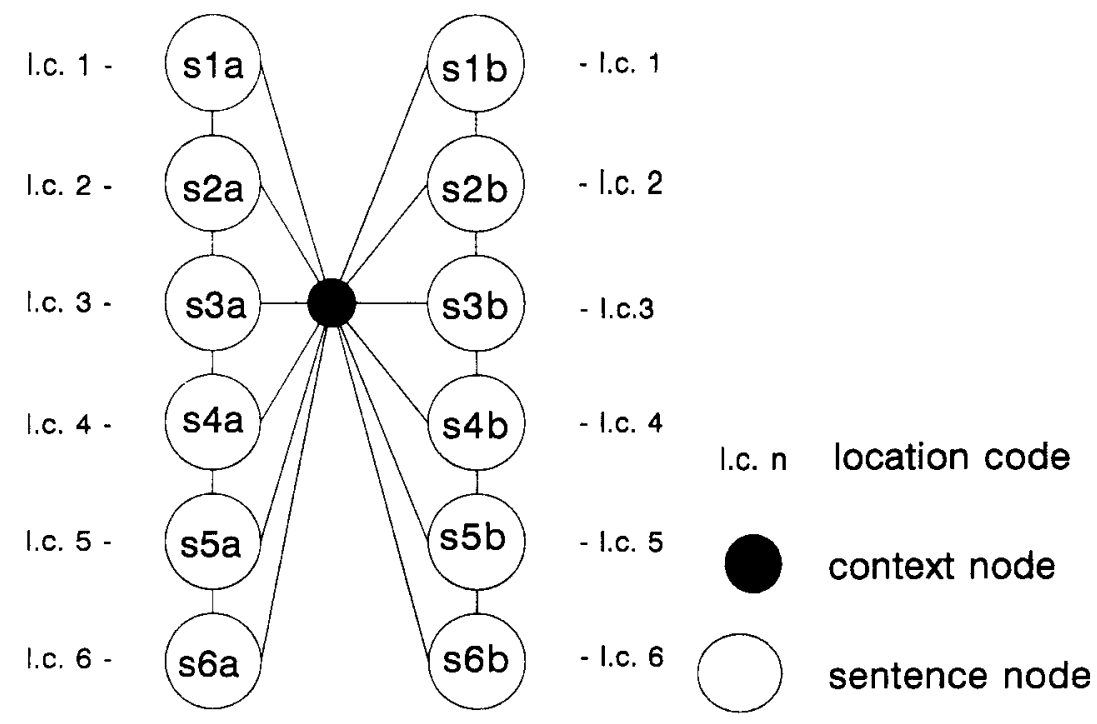

Representation B
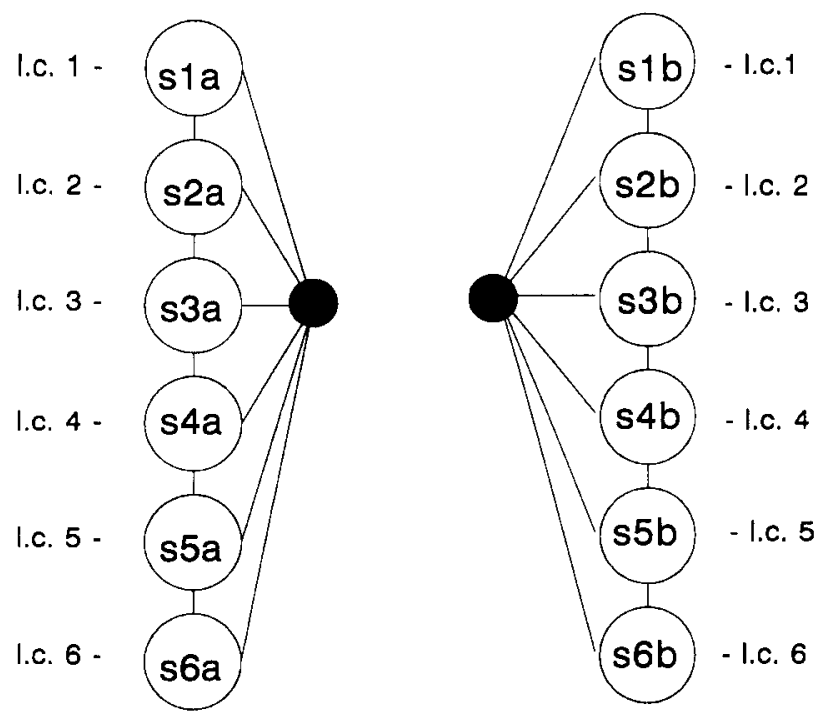

Figure 4. Diagrams of the two network representations that were considered for the text pair of Experiment 2.

rate decrease with decreases in the degree of network connection between the nodes for the probe words. In both of the possible representations, degree of network connection is constant as a function of surface position difference. In Representation A, the nodes for any pair of sentences from different texts are connected to the same degree, because all paths between the nodes have to pass through the context node. In Representation B, the nodes for any pair of sentences from different texts are completely unconnected, because the nodes for the sentences in the two texts are connected to different context nodes.
Thus, the hypothesis predicts that RT and error rate on different-text trials will be constant as a function of surface position difference.

\section{Predictions of the Location Code Hypothesis}

According to the location code hypothesis, negative SM RT and error rate decrease with increases in the difference between the location codes that are accessed with the probe words. If the location codes for the two texts are confusable, the location code difference for different-text probes will increase with increases in surface position 

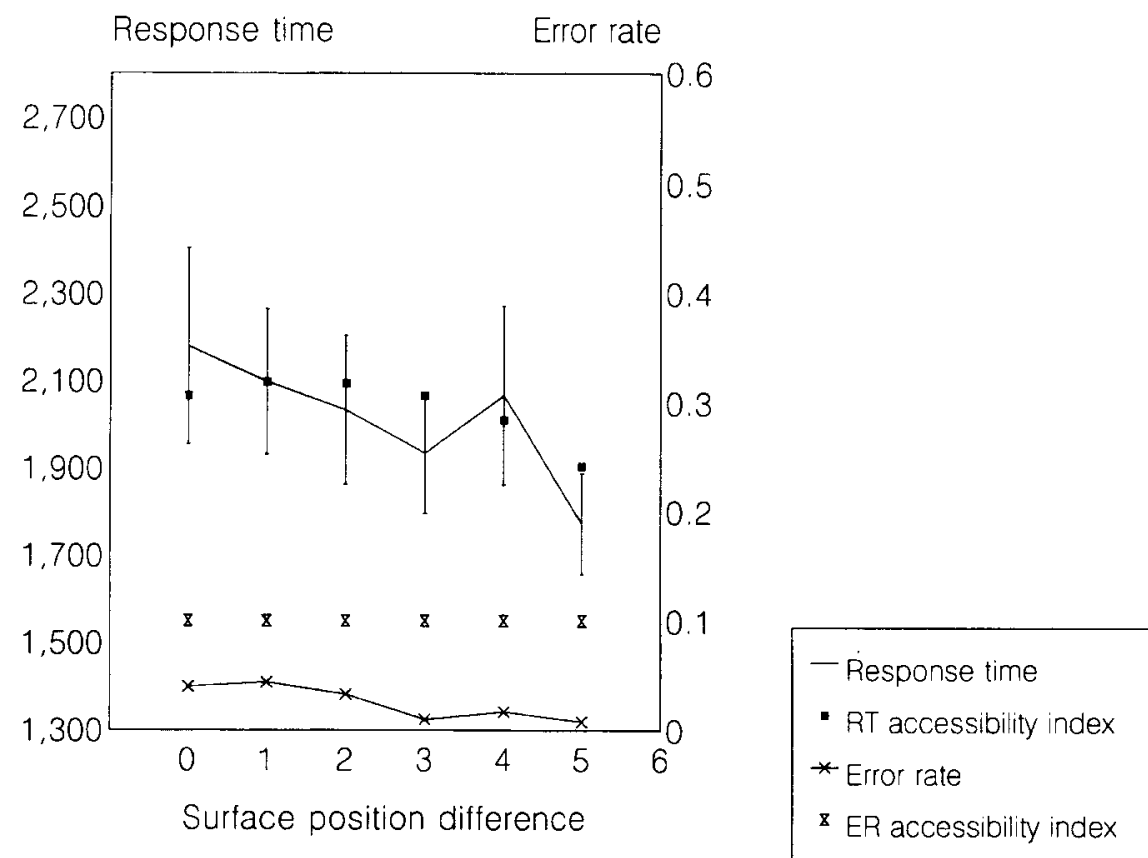

Figure 5. Experiment 2: Performance on different-text trials and accessibility indices as a function of surface position difference.

difference. RT and error rate will decrease with increases in surface position difference.

\section{Method}

Subjects. The subjects were 12 students from a class in introductory psychology at Columbia College.

Materials. There were 180 different-text probes. They were constructed by (1) forming the 36 possible unordered pairs of the six sentences in the two texts, and (2) forming five pairs of words for each of these pairs of sentences by (a) forming the four pairs of words that could be formed, in which one of the words was a noun that identified a character, the other word was a verb, and the two words came from different sentences, and (b) randomly selecting one of the four word pairs for repeated presentation.

There were also 30 same-text probes, consisting of words from different sentences in the same text. They were included primarily to encourage the subjects to emit negative responses on the basis of cognitive distance. If all of the negative probes had been different-text probes, the subjects would have been more likely to emit negative responses on the basis of the fact that the probe words came from different texts. The same-text probes were constructed by (1) forming, for each text, all possible unordered pairs of its sentences, and (2) choosing, at random, for each sentence pair, one of the four pairs of words that could be formed with the procedure used for different-text probes. Words that were repeated in adjacent sentences were not used, as in Experiment 1.

Notice that the negative probes for this experiment resembled the probes for Experiment 1 in that (1) there were unequal numbers of negative probes for the different levels of surface position difference and (2) the different surface positions were unequally represented in the probes for the different levels of surface position difference. In fact, this was the case in all of the experiments of this study.

There were also 216 positive probes. They were constructed in the same way as the positive probes for Experiment 1.

Procedure. At the beginning of the session, the subjects learned each of the texts in turn, in the manner of Experiment 1. The order of acquisition was counterbalanced across subjects. The subjects were told that the words in the test probes would be drawn in some cases from the same text and in some cases from different texts. They were asked to indicate, for each probe, whether or not the words came from the same sentence.

\section{Results and Discussion}

RT and error rate for different-text trials decreased with increases in surface position difference (see Figure 5). The effect of surface position difference in the RT data was nearly significant $\left[F(5,55)=3.15, M S_{\mathrm{e}}=77,862, p<\right.$ $.07]$, and the linear component of this effect was clearly significant $\left[F(1,11)=6.94, M S_{\mathrm{e}}=122,741, p<.05\right]$. The effect of surface position difference and the linear trend were both significant in the error rate data [surface position difference, $F(5,55)=2.57, M S_{\mathrm{e}}=.001, p<.05$; linear trend, $\left.F(1,11)=6.84, M S_{\mathrm{e}}=0.002, p<.05\right]$.

Although the RT accessibility index decreased as a function of surface position difference, this decrease was not statistically significant $\left[F(1,11)=4.22, M S_{\mathrm{e}}=49,364\right.$, $p>.05]$. The error rate accessibility index was constant as a function of surface position difference. Therefore, the effect in the surface position difference data cannot be attributed to variation in accessibility.

There were so few same-text trials that the data for these trials were not systematically analyzed.

These results support the location code hypothesis over the network connection hypothesis. On the basis of this finding, it was possible to proceed with the project of finding support for the argument overlap and causal cohesion hypotheses. Recall that the plan was to produce patterns of negative SM performance that reflected net- 
works predicted by these two representation hypotheses. In order to do this, it was necessary to specify how information about the relative position of pairs of words in network representations was translated into negative SM performance. Two process hypotheses were considered with respect to this question. The present results support the location code hypothesis.

\section{EXPERIMENT 3}

Before proceeding with the primary objective of finding support for the two representation hypotheses, it was necessary to answer one more preliminary question. The ultimate objective was to show that SM performance reflected network representations predicted by the argument overlap and causal coherence hypotheses. It was not clear from the results of Experiments 1 and 2, however, that SM performance reflected network representations. Because the texts for these experiments were represented in networks that paralleled their surface forms, the crucial factor in determining the observed distance effects may have been either network distance or surface distance. Experiment 3 was conducted to show that negative SM performance depends on network rather than surface distance.

The strategy in this experiment was to use a stimulus text with a network representation that (1) was uncontroversial with respect to the two representation hypotheses and (2) did not parallel surface form. The object was to demonstrate that negative SM performance depended on distance in this text's predicted network representation rather than distance in its surface form.

The stimulus text for the experiment is shown in Table 2 . The argument overlap and causal coherence hypotheses both predict that this text will be represented in terms of a network with the branching structure shown in Figure 6. Notice that the node for the text's fifth sentence is linked to the node for its first sentence rather than to the node for its fourth sentence. Thus, the first four sentences and the last four sentences of the text are represented in different branches of the network.

As a consequence of the branching structure of the stimulus text, two distinct sets of distances were associated with the pairs of words that were used as probes in the SM task: the distances that were given by text's surface form, and the distances that were given by its predicted network representation. For example, Sentences 4

Table 2

Stimulus Text for Experiment 3

(S1) Once there was a graduate student, who generated a genie in the laboratory. (S2) The genie produced a go-go girl. (S3) Soon the gogo girl offended the priest. (S4) And the priest complained to the dean. (S5) But the graduate student had already reported the breakthrough to the President, in Washington. (S6) The President had informed an operative. (S7) The operative had planted the information with the Russians. (S8) The Russians had dispatched a diplomat to sue for peace.

Note-SI, S2, .. $=$ Sentence 1 , Sentence 2, etc.

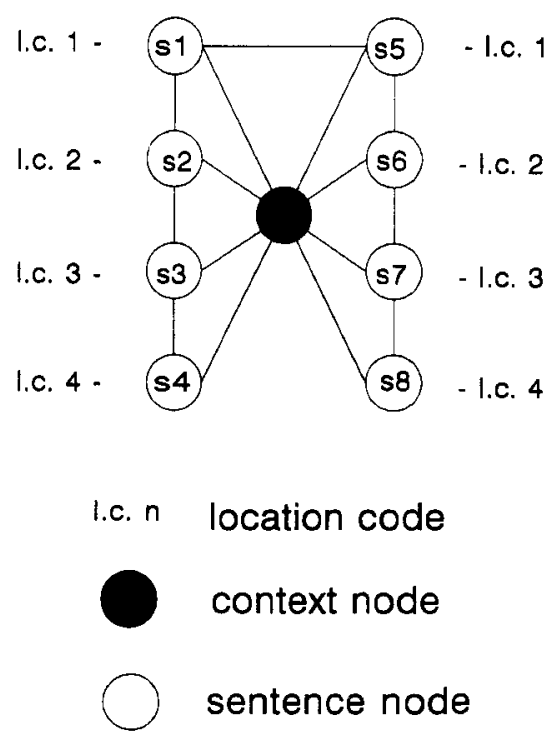

Figure 6. Diagram of the network representation that was assumed for the text of Experiment 3

and 5 are close in the text's surface form yet distant in the network representation. On the other hand, Sentences 1 and 5 are distant in the text's surface form yet close in the network representation.

Recall that the point of the experiment was to show that negative SM performance depends on network rather than surface distance. In order to do this, assumptions had to be made about the process whereby relative network position is translated into SM performance. The location code hypothesis was assumed as an account of this process because it had been supported over the network connection hypothesis in Experiment 2. Thus, the key predictions were made on the basis of this hypothesis. In addition, a second set of predictions was made on the basis of the network connection hypothesis in order to further disconfirm this hypothesis. The crucial trials for both sets of predictions were the different-branch trials, the negative trials upon which the probe words came from different branches of the text.

\section{Predictions If SM Performance Depends on Network Distance and the Location Code Hypothesis Is Correct}

In this case, it is predicted that RT and error rate will be concave downward as a function of surface position difference. The reasoning is as follows.

The most straightforward way of assigning location codes to the sentences of the stimulus text is shown in Figure 6. In this scheme, the code for a given sentence records its ordinal position in the branch to which it belongs (there may be other codes that record the branch to which the sentence belongs). It can be shown through simple computation (see Table 3) that the difference between the location codes for the pairs of probe words is concave upward as a function of the surface position dif- 
Table 3

Experiment 3: Predictions of the Competing Hypotheses

\begin{tabular}{|c|c|c|c|c|}
\hline $\begin{array}{c}\text { Sentence } \\
\text { Pair }\end{array}$ & $\begin{array}{c}\text { Surface } \\
\text { Position } \\
\text { Difference }\end{array}$ & $\begin{array}{l}\text { Location } \\
\text { Code } \\
\text { Difference }\end{array}$ & $\begin{array}{c}\text { Degree of } \\
\text { Network } \\
\text { Connection }\end{array}$ & $\begin{array}{c}\text { Distance } \\
\text { From Middle } \\
\text { of Text }\end{array}$ \\
\hline $4-5$ & 1 & 3 & 4 & 0 \\
\hline $\begin{array}{l}3-5 \\
4-6\end{array}$ & $\begin{array}{l}2 \\
2\end{array}$ & $\begin{array}{l}2 \\
2\end{array}$ & $\begin{array}{c}3 \\
5 \\
M=4\end{array}$ & $\begin{array}{l}1 \\
1\end{array}$ \\
\hline $\begin{array}{l}2-5 \\
3-6 \\
4-7\end{array}$ & $\begin{array}{l}3 \\
3 \\
3\end{array}$ & $\begin{array}{l}1 \\
1 \\
1\end{array}$ & $\begin{array}{c}2 \\
4 \\
6 \\
M=4\end{array}$ & $\begin{array}{l}2 \\
2 \\
2\end{array}$ \\
\hline $\begin{array}{l}1-5 \\
2-6 \\
3-7 \\
4-8\end{array}$ & $\begin{array}{l}4 \\
4 \\
4 \\
4\end{array}$ & $\begin{array}{l}0 \\
0 \\
0 \\
0\end{array}$ & $\begin{array}{c}1 \\
3 \\
5 \\
7 \\
M=4\end{array}$ & $\begin{array}{l}3 \\
3 \\
3 \\
3\end{array}$ \\
\hline $\begin{array}{l}1-6 \\
2-7 \\
3-8\end{array}$ & $\begin{array}{l}5 \\
5 \\
5\end{array}$ & $\begin{array}{l}1 \\
1 \\
1\end{array}$ & $\begin{array}{c}2 \\
4 \\
6 \\
M=4\end{array}$ & $\begin{array}{l}4 \\
4 \\
4\end{array}$ \\
\hline $\begin{array}{l}1-7 \\
2-8\end{array}$ & $\begin{array}{l}6 \\
6\end{array}$ & $\begin{array}{l}2 \\
2\end{array}$ & $\begin{array}{c}3 \\
5 \\
M=4\end{array}$ & $\begin{array}{l}5 \\
5\end{array}$ \\
\hline $1-8$ & 7 & 3 & 4 & 6 \\
\hline
\end{tabular}

ference associated with the words. According to the location code hypothesis, negative SM RT and error rate decrease with increases in location code difference. It follows that RT and error rate will be concave downward as a function of surface position difference.

\section{Predictions If SM Performance Depends on Network Distance and the Network \\ Connection Hypothesis Is Correct}

In this case, it is predicted that RT and error rate will be constant as a function of surface position difference. The reasoning is as follows.

In the network assumed for the stimulus text (see Figure 6), there are two paths between any pair of sentence nodes: one path that involves visiting the context node, and another that involves traversing the chain of sentence nodes. The former path is equally long for any pair of sentence nodes. It can be shown computationally (see Table 3) that the distance in the latter path is constant as a function of surface position difference. It follows that degree of network connection, and thus RT and error rate, will be constant as a function of surface position difference. The predictions of the different hypotheses for the results of the experiment are summarized in Table 4.

\section{Predictions If SM Performance Depends on Surface Distance}

In this case, it is predicted that RT and error rate will decrease monotonically with surface position difference as in Experiments 1 and 2.

\section{Predictions If SM Performance Depends on Surface Position}

Are there other bases upon which we might predict variation in SM performance as a function of surface position difference? One possibility is that performance will vary as a by-product of the surface position effect and/or end anchor effect that was noted in the Discussion section of Experiment 1.

It can be demonstrated that, in this case, RT and error rate will decrease as a function of surface position difference. The reasoning runs as follows: If performance varies as a by-product of the surface position and/or end anchor effect, RT and error rate will decrease as a function of the combined distance of the probe words from the middle of the text. Distance from the middle increases as a function of surface position difference (see Table 3 ). It follows that RT and error rate will decrease as a function of surface position difference. (Notice that distance from the middle of the text is completely correlated here with surface position difference. Whereas these two factors were independent in the analysis of results from Experiment 1 , they are completely correlated in the present analysis because only the different-branch trials are considered.)

Table 4

Patterns of Response Time and Error Rate Predicted as a Function of Surface Position Difference Under the Different Hypotheses

\begin{tabular}{|c|c|c|c|}
\hline \multicolumn{2}{|c|}{ Argument Overlap } & \multicolumn{2}{|c|}{ Causal Coherence } \\
\hline $\begin{array}{l}\text { Location Code } \\
\text { Difference }\end{array}$ & $\begin{array}{c}\text { Network } \\
\text { Connection }\end{array}$ & $\begin{array}{l}\text { Location Code } \\
\text { Difference }\end{array}$ & $\begin{array}{c}\text { Network } \\
\text { Connection }\end{array}$ \\
\hline \multicolumn{4}{|c|}{ Experiment 3} \\
\hline Concave down & Constant & Concave down & Constant \\
\hline \multicolumn{4}{|c|}{ Experiment 4 : Text $\mathrm{A}$} \\
\hline Concave down & Constant & & \\
\hline \multicolumn{4}{|c|}{ Experiment 4 : Text $\mathrm{B}$} \\
\hline & & Concave down & Constant \\
\hline \multicolumn{4}{|c|}{ Experiment 5} \\
\hline Concave down & Constant & Linear decrease* & Linear decrease* \\
\hline \multicolumn{4}{|c|}{ Experiment 6} \\
\hline Linear decrease* & Linear decrease & Concave down & Constant \\
\hline
\end{tabular}

*Also predicted if SM performance depends on surface distance. 


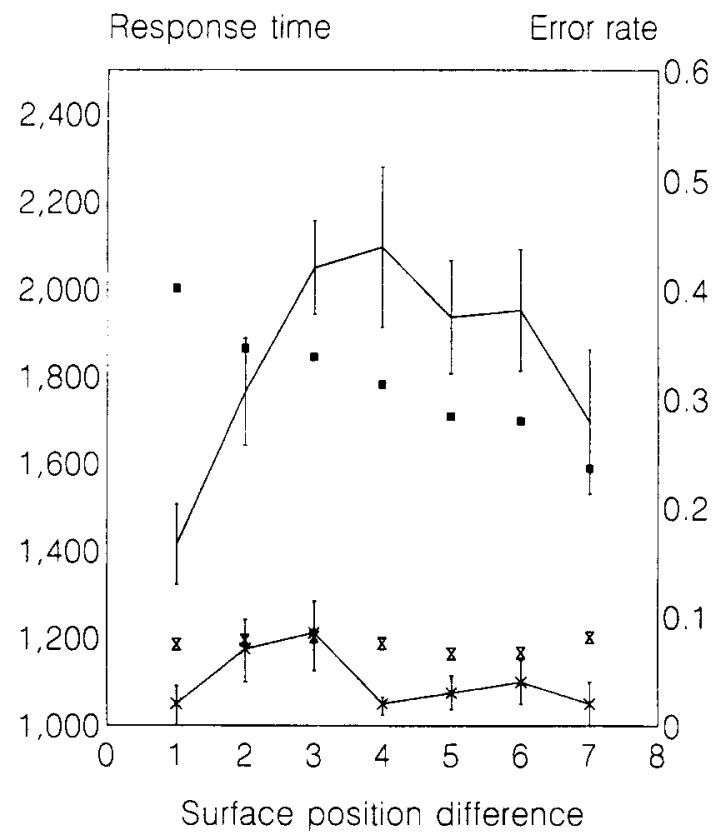

$$
\begin{aligned}
& \text { - Response time } \\
& \text { - RT accessibility index } \\
& \text { * Error rate } \\
& \text { × ER accessibility index }
\end{aligned}
$$

Figure 7. Experiment 3: Performance on different-branch trials and accessibility indices as a function of surface position difference.

In summary, the experiment had the following rationale: If RT and error rate are concave downward as a function of surface position difference, this implies that SM performance depends on network distance and that the location code hypothesis is correct. If RT and error rate are constant as a function of surface position difference, this implies that SM performance depends on network distance and that the network connection hypothesis is correct. If RT and error rate decrease as a function of surface position difference, this implies that SM performance depends on surface distance and/or distance from the middle of the text (as in the surface position and end anchor effects).

\section{Method}

Subjects. The subjects were 18 students from a class in introductory psychology at Columbia College. They participated in fulfillment of a course requirement.

Materials. There were 96 different-branch probes. They were constructed by (1) forming the 16 possible unordered pairs of the four sentences in the two branches of the text, and (2) forming six pairs of words for each of these pairs of sentences by (a) forming the four pairs of words that could be formed, in which one of the words was a noun that identified a character, the other word was a verb, and the two words came from different sentences, and (b) randomly selecting two of the four word pairs for repeated presentation. For the Sentence Pair 1-5, the word that appeared in both sentences was not used in any of the word pairs.

There were 12 same-branch probes. They were included to encourage the subjects to base their negative responses on cognitive distance (rather than judgments as to which branch the words came from). They were constructed in the same way as the sametext probes for Experiment 2.
There were 96 positive probes. They were obtained in the same way as the probes for the positive trials of Experiment 1, except that each word pair was presented twice.

Procedure. The procedure was the same as for Experiment 1.

\section{Results and Discussion}

RT and error rate for different-branch trials were concave downward as a function of surface position difference (see Figure 7). The effect of surface position difference in the RT data was significant $\left[F(6,102)=4.81, M S_{\mathrm{e}}=\right.$ $211,759, p<.005]$. The quadratic component of this effect was significant $\left[F(1,17)=11.83, M S_{\mathrm{e}}=415,492\right.$, $p<.005]$. The effect of surface position difference in the error rate data was nearly significant $[F(6,102)=2.00$, $\left.M S_{\mathrm{e}}=0.007, p=.11\right]$. The quadratic component of this effect was also nearly significant $\left[F(1,17)=3.54, M S_{\mathrm{e}}=\right.$ $0.003, p=.08]$.

The RT and error rate accessibility indexes varied monotonically with surface position difference (quadratic trend, $F \mathrm{~s}<1$ ). The pattern in the different-branch data therefore cannot be attributed to variation in probe-word accessibility.

These results suggest that negative SM performance reflects the network representations of texts. They also provide further support for the location code hypothesis. This hypothesis predicts the concave-downward pattern in the data under the assumption that SM performance reflects network distance. The network connection hypothesis, in contrast, predicts that RT and error rate will be constant as a function of surface position difference if SM performance reflects network distance. 
Table 5

Experiment 3: Performance on Different-Branch Trials as a Function of Surface Position

\begin{tabular}{|c|c|c|c|c|}
\hline \multirow{2}{*}{$\begin{array}{c}\text { Surface Position } \\
\text { in Branch } 1 \\
\end{array}$} & \multicolumn{4}{|c|}{ Surface Position in Branch 2} \\
\hline & 5 & 6 & 7 & 8 \\
\hline \multicolumn{5}{|c|}{ Response Time (Milliseconds) } \\
\hline 1 & 2,157 & 1,819 & 1,988 & 1,698 \\
\hline 2 & 1,976 & 2,555 & 1,981 & $1,92 !$ \\
\hline 3 & 1,758 & 2,143 & 1,985 & 2,014 \\
\hline \multirow[t]{5}{*}{4} & 1,415 & 1,775 & 2,034 & 1,693 \\
\hline & 2,157 & & & \\
\hline & 1,897 & 2,555 & & \\
\hline & 1,873 & 2,062 & 1,985 & \\
\hline & 1.556 & 1,848 & 2,024 & 1,693 \\
\hline \multicolumn{5}{|c|}{ Error Rate } \\
\hline 1 & .019 & .057 & .074 & .019 \\
\hline 2 & .057 & .019 & .019 & .000 \\
\hline 3 & .075 & .112 & .019 & .019 \\
\hline 4 & .019 & .065 & .084 & .019 \\
\hline
\end{tabular}

In order to find further support for the location code hypothesis, the data for the different-branch trials were also analyzed as a function of surface position in the two branches of the text (see Table 5). The results of this analysis can be characterized roughly as follows: (1) RT for probes in which one of the words came from the beginning of its branch (the first rows and columns of the array) decreased as a function of the position of the sentence to which the other word belonged. (2) RT for probes in which one of the words came from the end of its branch (the last rows and columns of the array) increased as a function of the position of the sentence to which the other word belonged. (There was, in addition, a slight end anchor effect. RT for probes in which both of the words came from the ends of their branches was relatively short.)

Both of the major patterns in the data are consistent with the location code hypothesis. If one of the words in a probe comes from the beginning of its branch, the location code difference for the probe will increase with increases in the surface position of the other word; if one of the words in a probe comes from the end of its branch, the location code difference for the probe will decrease with increases in the surface position of the other word.

On the other hand, only the first of these patterns is consistent with the network connection hypothesis. This hypothesis predicts that RT will decrease as a function of surface position in either branch of the text, since the de- gree of network connection will decrease with surface position in either branch.

In order to reinforce the conclusion that SM performance depends on network as opposed to surface distance and, at the same time, provide further support for the location code hypothesis, the data for the differentbranch trials were examined with regression analyses (Lorch \& Myers, 1990). Separate analyses were conducted to fit the RT and the error rate data. Each subject contributed 16 data points to each analysis; these were the mean RTs and error rates for the 16 combinations of surface position that were obtained by crossing the four surface positions in the first branch of the text with the four positions in the second branch.

An attempt was first made to fit the data in terms of the location code hypothesis (the values are shown in the first array of Table 6). A parallel attempt was made to fit the data in terms of the network connection hypothesis, as follows: It was noted above that there are two paths between any pair of sentence nodes in the network representation of the text and that one of these paths is equally long for any pair of nodes. An attempt was therefore made to predict performance on the basis of the length of the path whose length varies for different pairs of nodes (the values are shown in the second array of Table 6).

Several variables were included in each regression equation to control for nuisance factors: (1) a surface position variable that increased with the surface position difference associated with the probe words and their distance from the middle of the text (this variable thus controlled for two important factors that were, as was noted above, completely correlated here-the values of this variable are shown in the third array of Table 6; for comparison, distance from the middle of the text is shown in the fourth array of the same table), (2) an end anchor variable that was I for trials on which the probe words came from the first and/or last sentences in the text and 0 for all other trials (the values are shown in the fifth array of Table 6), and (3) an accessibility variable that was derived from performance on positive trials as in earlier analyses.

Location code difference was a significant predictor of the RT data $\left[F(1,17)=7.75, M S_{\mathrm{c}}=880,286, p<.05\right]$, accounting for $5 \%$ of the variance in these data. Degree of network connection was not a significant predictor $(F<1)$. Of the control variables, only the end anchor variable had a statistically significant impact $[F(1,17)=$

Table 6

Values of Predictor Variables Used in the Regression Analyses of the Data for Experiments $3-8$

\begin{tabular}{|c|c|c|c|c|c|c|c|c|c|c|c|c|c|c|c|c|c|c|c|c|}
\hline \multirow{2}{*}{$\begin{array}{c}\text { Surface } \\
\text { Position } \\
\text { in Branch } 1\end{array}$} & \multicolumn{4}{|c|}{$\begin{array}{c}\text { Location Code } \\
\text { Difference }\end{array}$} & \multicolumn{4}{|c|}{$\begin{array}{c}\text { Length of } \\
\text { Network Path }\end{array}$} & \multicolumn{4}{|c|}{$\begin{array}{c}\text { Surface Position } \\
\text { Variable }\end{array}$} & \multicolumn{4}{|c|}{$\begin{array}{l}\text { Distance From } \\
\text { Middle of Text }\end{array}$} & \multicolumn{4}{|c|}{$\begin{array}{c}\text { End Anchor } \\
\text { Variable }\end{array}$} \\
\hline & 5 & 6 & 7 & 8 & 5 & 6 & 7 & 8 & 5 & 6 & 7 & 8 & 5 & 6 & 7 & 8 & 5 & 6 & 7 & 8 \\
\hline 1 & 0 & 1 & 2 & 3 & 1 & 2 & 3 & 4 & 4 & 5 & 6 & 7 & 3 & & 5 & 6 & & & & 1 \\
\hline 2 & 1 & 0 & 1 & 2 & 2 & 3 & 4 & 5 & 3 & 4 & 5 & 6 & 2 & 3 & 4 & 5 & 0 & 0 & 0 & 1 \\
\hline 3 & 2 & 1 & 0 & 1 & 3 & 4 & 5 & 6 & 2 & 3 & 4 & 5 & 1 & 2 & 3 & 4 & 0 & 0 & 0 & 1 \\
\hline 4 & 3 & 2 & 1 & 0 & 4 & 5 & 6 & 7 & 1 & 2 & 3 & 4 & 0 & I & 2 & 3 & 0 & 0 & 0 & 1 \\
\hline
\end{tabular}


$\left.11.70, M S_{\mathrm{e}}=219,125, p<.01\right]$, accounting for $2 \%$ of the variance in the data. None of the variables accounted for significant amounts of the variance in the error rate data.

Two general conclusions can be drawn from these results. First, the results imply that the branching network predicted by the two representation hypotheses was reflected in SM performance and, thus, that SM performance depends on network rather than surface distance. Second, the results offer further support for the location code hypothesis over the network connection hypothesis. The location code hypothesis does not account for a large proportion of the variance in the data, but it must be remembered that the SM task is reasonably complex and that cognitive distance is only one of the factors upon which subjects base their responses.

\section{EXPERIMENT 4}

Experiment 4 was an attempt to collect evidence that the argument overlap and causal coherence hypotheses are important in explaining the representation of text in memory. The texts for the experiment are presented in Table 7. The argument overlap hypothesis predicts that Text A will be represented in a branching network (see Figure 6); the causal coherence hypothesis is not an integrative factor in this text. The causal coherence hypothesis predicts that Text $\mathrm{B}$ will be represented in a branching network; the argument overlap hypothesis is not a factor in this text.

The general objective in Experiment 4 was to produce patterns of SM performance that reflected the branching networks predicted by the two hypotheses. Specifically, the plan was to show that RT and error rate for negative different-branch trials were concave downward as a function of surface position difference. The rationale here was the same as in Experiment 3. Past results had supported the location code hypothesis over the network connection hypothesis, and the location code hypothesis predicts that RT and error rate will be concave downward if the texts are represented in branching networks. (As

Table 7

Stimulus Texts for Experiment 4

\section{Text A}

(S1) For some reason, the seamstress distrusted the butcher. (S2) The butcher, however, was cheating the librarian. (S3) The librarian, in turn, feared the cook. (S4) And the cook was blackmailing the nurse (S5) The seamstress also hated the minister. (S6) But the minister was poisoning the dentist. (S7) The dentist, however, suspected the tailor. (S8) And the tailor was spying on the pharmacist.

$$
\text { Text } B
$$

(S1) Midway through the afternoon performance of the greatest show on earth, a schoolboy booed the liontamer. (S2) The ringmaster immediately reported the incident. (S3) The magician then became very depressed. (S4) The clowns had to perform therapy. (S5) Meanwhile, an usher had videotaped the outburst. (S6) Upon viewing the tape, the owner had sought advice. (S7) The market researcher had advocated a change. (S8) The agent had engaged a rock stat for the evening show.

Note-SI, $\mathrm{S} 2, \ldots=$ Sentence 1 , Sentence 2 , etc. before, the network connection hypothesis predicts that RT and error rate will be constant as a function of surface position difference if the texts are represented in branching networks.) The predictions of the different hypotheses for the results of the experiment are summarized in Table 4.

It was reasoned that SM performance would reflect the surface forms of the texts if they were not represented in branching networks. The following pattern was predicted in this case: Negative RT and error rate will decrease monotonically with surface position difference. This will be true if performance reflects the surface distance between the probe words or the distance of the probe words from the middle of the text. This follows from the fact that surface distance is completely correlated with distance from the middle for different-branch trials (as was shown in the presentation of Experiment 3; see Table 3).

\section{Method}

Subjects. The subjects were 14 students from a class in introductory psychology at George Washington University.

Materials. Since relationships of argument overlap can be extracted from the surface form of a text, construction of the argument overlap text was straightforward. The causal coherence text was constructed so that a branching network would be predicted on the basis of a set of criteria proposed by Trabasso and his colleagues (c.g., Trabasso \& Sperry, 1985). Specifically, it was required that the following series of steps produce a branching network: (1) represent the text's sentences with event nodes (note that each sentence in the text described an event), (2) group together every pair of nodes for which it is the case that the occurrence of one of the two corresponding events is necessary under the circumstances for the occurrence of the other event, and (3) assemble the nodes into a network in which only those pairs of nodes are linked for which it is the case that the occurrence of one of the corresponding events provides the immediate precondition for the occurrence of the other event (allow the rest of the causal relationships to be given by the principle of transitivity).

In order to verify that the causal coherence hypothesis predicted a branching network for the text, 3 graduate student judges were asked to sketch network representations for the text according to the criteria that were used in constructing it. All of the judges produced networks with the branching structure depicted in Figure 6. In the Discussion section of Experiment 6, data will be reported suggesting that a larger sample of undergraduates also perceived the causal relationships in the text as following the intended pattern.

All of the word-pair probes consisted of words from the same text, with the probes for the two texts being intermixed in a single test sequence. The probes for each text were constructed as in Experiment 3.

Procedure. The procedure was the same as for Experiment 2.

\section{Results and Discussion}

For both texts, RT and error rate on different-branch trials were concave downward as a function of surface position difference (see Figure 8 ). The accessibility index was included as a covariate in the analyses of the RT data for the two texts, because ANOVAs revealed that the index showed significant quadratic patterns as a function of surface position difference. The analyses of covariance (ANCOVAS) revealed significant effects of surface position difference in the data for the argument 


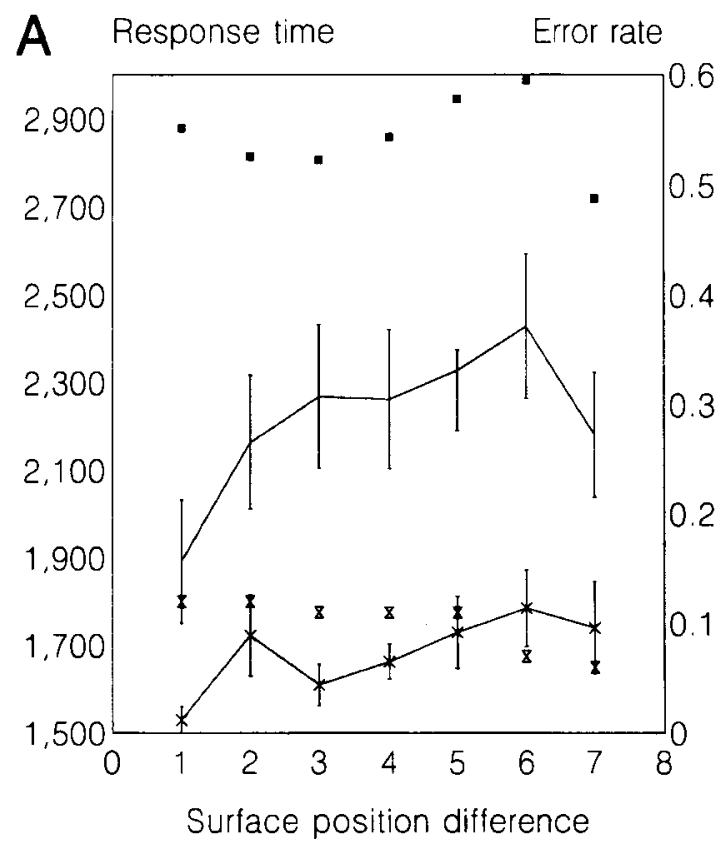

$$
\begin{aligned}
& \text { - Response time } \\
& \text { - RT accessibility index } \\
& \text { * Error rate } \\
& \text { × ER accessibility index }
\end{aligned}
$$

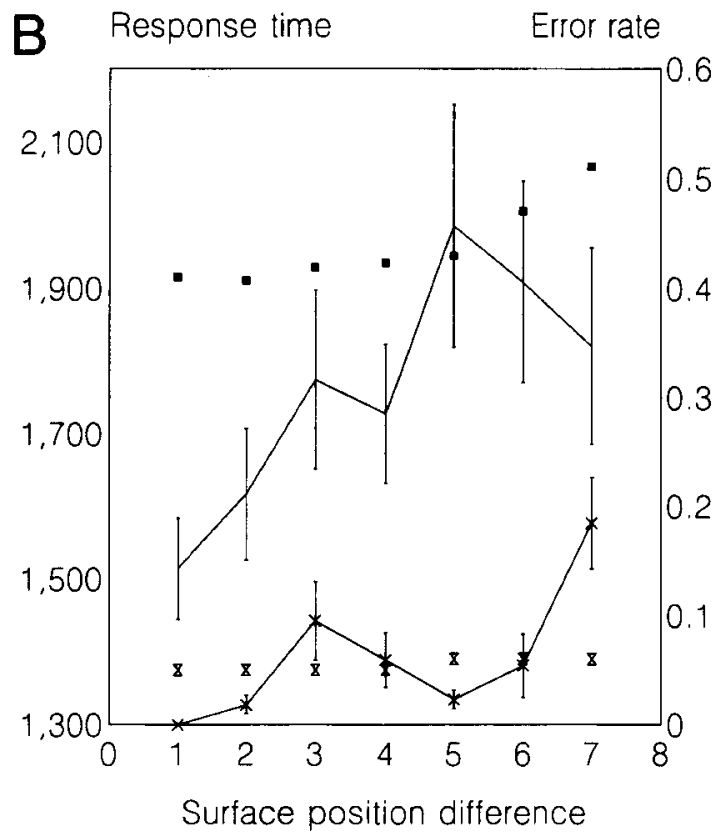

$$
\begin{aligned}
& \text { - Response time } \\
& \text { - RT accessibility index } \\
& \text { * Error rate } \\
& \text { × ER accessibility index }
\end{aligned}
$$

Figure 8. Experiment 4: Performance on different-branch trials and accessibility indices for Texts $A$ and $B$ as a function of surface position difference.

overlap text [Text A, $F(6,77)=4.91, M S_{\mathrm{e}}=73,367, p<$ $.005]$ and the causal coherence text [Text B, $F(6,77)=$ $\left.6.92, M S_{\mathrm{e}}=53,624, p<.0005\right]$. Trend analyses revealed significant quadratic components in these effects [argument overlap, $F(1,12)=5.30, M S_{\mathrm{e}}=10,248, p<.05$; causal coherence, $F(1,12)=4.86, M S_{\mathrm{e}}=74,842, p<$ $.05]$.
The accessibility index was included as a covariate in the analysis of the error rate data for the argument overlap text, because an ANOVA revealed that the index showed a significant quadratic pattern as a function of surface position difference. The ANCOVA showed that quadratic trend in the data was not significant $[F(1,12)<1]$. An ANOVA showed a significant effect of surface posi- 
tion difference in the error rate data for the causal coherence text $\left[F(6,78)=7.10, M S_{\mathrm{e}}=0.008, p<.001\right]$, with a quadratic trend that was nearly significant $[F(1,13)=$ $\left.2.52, M S_{\mathrm{e}}=0.008, p=.136\right]$. The error rate accessibility index for this text did not vary as a function of surface position difference $(F<1)$. These results suggest that the networks predicted by the argument overlap and causal coherence hypotheses are reflected in SM performance.

In order to reinforce these conclusions, the data for the different-branch trials were examined with regression analyses, as in Experiment 3. Because earlier results had supported the location code hypothesis over the network connection hypothesis, the former hypothesis was assumed in the regression model. Specifically, an attempt was made to fit the RT and error rate data for each text in terms of the values of location code difference that were predicted under the assumption that the text was represented in a branching network. In other respects, the analyses followed those conducted on the data from Experiment 3. Location code difference did not account for a significant amount of the variance in the data for either text.

\section{EXPERIMENT 4A}

Because so little evidence was produced in the present study for the causal coherence hypothesis, the results observed for Text $B$ in Experiment 4 were replicated in Experiment $4 \mathrm{~A}$ with a different text. RT and error rate for different-branch trials were concave quadratic functions of surface position difference. The effects in the RT and the error rate data were significant $[F(6,78)=3.40$, $M S_{\mathrm{e}}=38,574, p<.05$, and $F(6,78)=5.35, M S_{\mathrm{e}}=0.003$, $p<.005$, respectively], as were the quadratic components of these effects $\left[F(1,13)=8.17, M S_{\mathrm{e}}=59,729\right.$, $p<.05$, and $F(1,13)=6.44, M S_{\mathrm{e}}=0.003, p<.05$, respectively]. The RT and error rate accessibility indices did not vary significantly as a function of position difference $(F \mathbf{S}<1)$.

The data for the different-branch trials were also examined with regression analyses, as in Experiment 3. Location code difference was a significant predictor of the RT data $\left[F(1,13)=34.46, M S_{\mathrm{e}}=50,418, p<.001\right]$, accounting for $5 \%$ of the variance in these data. Of the control variables, only the accessibility variable had a statistically significant impact $\left[F(1,13)=10.14, M S_{\mathrm{e}}=\right.$ $127,836, p<.01]$, accounting for $3 \%$ of the variance in the data.

Location code difference in the branching network was a significant predictor of the error rate data $[F(1,13)=$ $\left.5.33, M S_{\mathrm{e}}=0.004, p<.05\right]$, accounting for $1.5 \%$ of the variance in these data. None of the control variables had a statistically significant impact.

The results of Experiments 4 and $4 \mathrm{~A}$ imply that the texts for these experiments were represented in branching networks predicted by the argument overlap and causal coherence hypotheses. In general, these results imply that texts are represented in memory as would be predicted by the two hypotheses.

\section{EXPERIMENT 5}

Experiment 5 was an attempt to obtain further support for the argument overlap hypothesis. This hypothesis predicts that the texts for the experiment will be represented in branching networks. The causal coherence hypothesis, on the other hand, predicts that the texts will be represented in linear networks---networks with structures that parallel surface form (a sample text is presented in Table 8).

In order to obtain evidence for the argument overlap hypothesis, the plan was to show that RT and error rate for different-branch trials were concave downward as a function of surface position difference. The rationale here was the same as in Experiments 3 and 4. Past results had supported the location code hypothesis over the network connection hypothesis, and the location code hypothesis predicts that RT and error rate will be concave downward if the texts are represented in branching networks (as before, the network hypothesis predicts that RT and error rate will be constant as a function of surface position difference if this is the case).

It was reasoned that if the texts were represented in linear networks, as predicted by the causal coherence hypothesis, RT and error rate for different-branch trials should decrease monotonically as a function of surface position difference. This follows under either the location code hypothesis or the network connection hypothesis. It was acknowledged, however, that RT and error rate would also decrease monotonically if they reflected surface distance. Thus, the predictions of the causal coherence hypothesis were more equivocal.

In summary, Experiment 5 had the following rationale: If RT and error rate are concave downward as a function of surface position difference, this implies that the texts are represented in the branching networks predicted by the argument overlap hypothesis. On the other hand, if RT and error rate decrease monotonically with surface position difference, this implies that the texts are represented in the linear networks predicted by the causal coherence hypothesis or possibly that SM performance reflects surface distance. The rationale for the experiment is summarized in Table 4.

The point of the experiment, then, was to gather further support for the argument overlap hypothesis-this time, in a situation in which it made predictions different from those of the causal coherence hypothesis. (An attempt was made in Experiment 6 to gather complementary support for the causal coherence hypothesis.) It should be stressed

Table 8

Sample Stimulus Text From Experiment 5

(S1) Midway through the matinee performance of the greatest show on earth, a gunman took a shot at the fire-eater. (S2) The fire-eater tossed his torch to the juggler. (S3) The yelping of the juggler excited the clowns. (S4) The clowns trampled the fat lady. (S5) Then the gunman seized the magician as a hostage. (S6) But the magician produced a midget from his hat. (S7)The midget reported the news to the ringmaster. (S8) The ringmaster dispatched the liontamer as a mediator.

Note-S1, S2, .. = Sentence 1. Sentence 2, etc. 

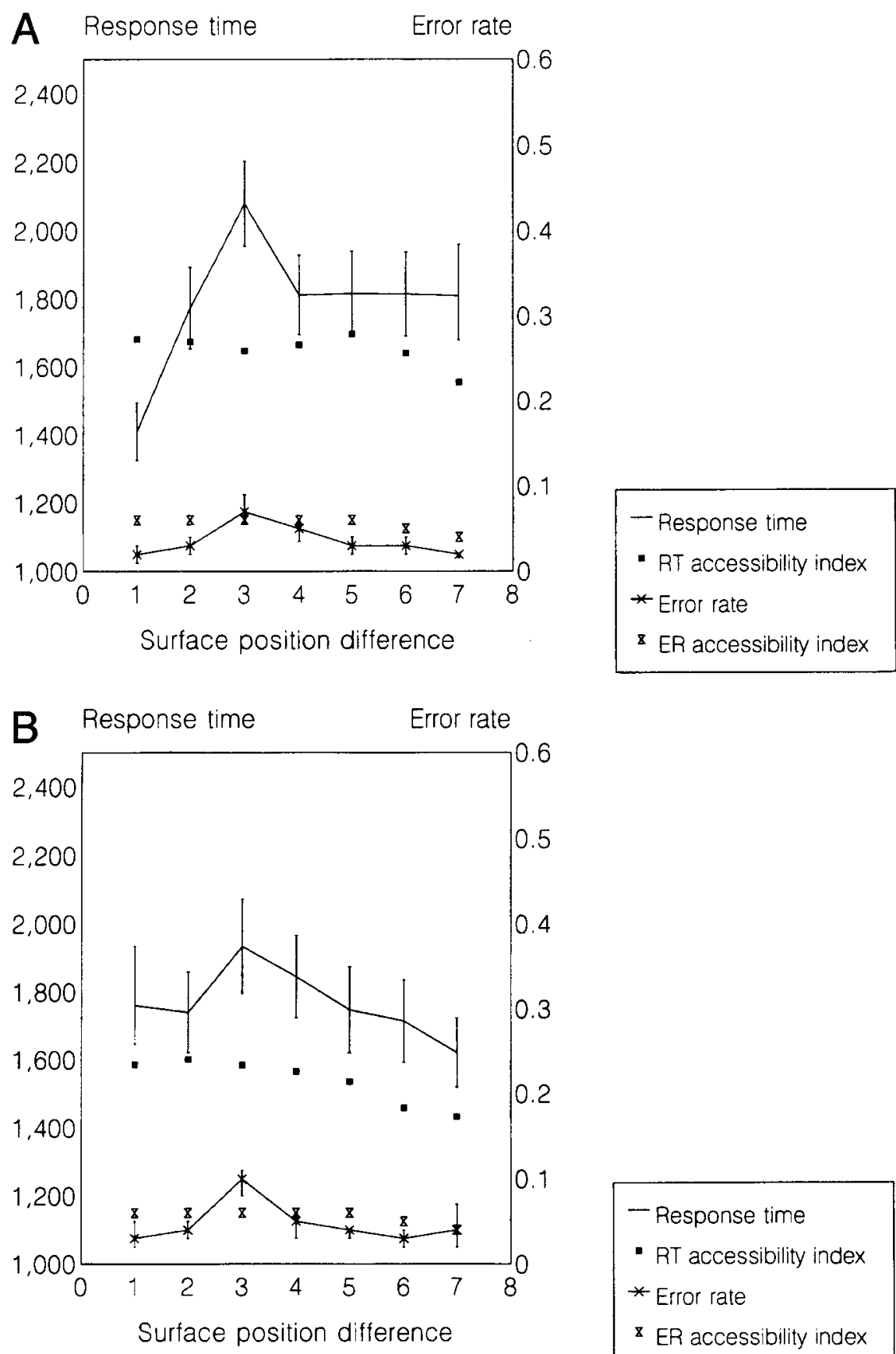

$$
\begin{aligned}
& \text { - Response time } \\
& \text { - RT accessibility index } \\
& \text { * Error rate } \\
& \text { x ER accessibility index }
\end{aligned}
$$

Figure 9. Experiment 5: Performance on different-branch trials and accessibility indices for Texts $A$ and $B$ as a function of surface position difference.

that the experiment was not a general test of the relative potency of the argument overlap and causal coherence hypotheses. Such a test would be difficult, because it would be difficult to equate argument overlap and causal coherence relationships for salience.

\section{Method}

Subjects. The subjects were 20 students from a class in introductory psychology at George Washington University.
Materials. The stimuli were two texts of the form shown in Table 8 . The predictions of the causal coherence hypothesis were verified with the procedure used in Experiment 4 . The probes were constructed in the same way as the probes for Experiment 3.

Procedure. The procedure was the same as for Experiment 2.

\section{Results and Discussion}

For both texts, RT and error rate on different-branch trials were concave quadratic functions of surface position 
difference (see Figure 9). An ANOVA revealed a significant surface position difference effect in the RT accessibility index for both texts. The accessibility index was therefore included as a covariate in the analyses of the RT data. The analyses revealed significant effects of surface position difference in the RT data for Text $\mathrm{A}[F(6,113)=$ $\left.12.12, M S_{\mathrm{e}}=63,705, p<.0001\right]$ and Text $\mathrm{B}[F(6,113)=$ $\left.3.00, M S_{\mathrm{e}}=66,372, p<.05\right]$. There was a significant quadratic component in the effect for Text $\mathrm{A}[F(1,18)=$ $\left.11.57, M S_{\mathrm{e}}=64,442, p<.01\right]$, but not in the effect for Text B $[F(1,18)<1]$.

ANOVAs revealed a significant effect of surface position difference in the error rate data for Text $\mathrm{A}[F(6,114)=$ $2.93, M S_{\mathrm{e}}=0.003, p<.05$ ] and a nearly significant effect of surface position difference in the data for Text B $\left[F(6,114)=2.48, M S_{\mathrm{e}}=0.004, p=.08\right]$. There was a significant quadratic component in the effect for Text $\mathrm{A}$ $\left[F(1,19)=9.52, M S_{\mathrm{e}}=0.002, p<.01\right]$ and a nearly significant quadratic component in the effect for Text B $\left[F(1,19)=2.54, M S_{\mathrm{e}}=0.003, p=.13\right]$. The error rate accessibility index did not vary as a function of surface position difference [Text A, $F(6,114)=1.37, M S_{\mathrm{e}}=$ $.001, p>.05 ;$ Text B, $F(6,114)=1.42, M S_{\mathrm{e}}=0.004, p>$ $.05]$.

The concave-downward patterns that were observed in the surface position difference analyses suggest that the stimulus texts were encoded in terms of the branching networks predicted by the argument overlap hypothesis. In order to gather further evidence that this was the case, the data for the different-branch trials were also examined with regression analyses. The key variables in each equation were (1) location code difference in the branching network and (2) a surface position variable - for a given test probe, this variable (a) had the same values as surface position difference and location code difference in the linear network and (b) was completely correlated with the distance of the probe words from the middle of the text (see Table 6).

In addition, several control variables were included in each equation: (1) an end anchor variable that was 1 for trials on which the probe words came from the first and/ or last sentences in the text and 0 for all other trials (see Array 5 of Table 6), and (2) an accessibility index that was derived from performance on positive trials as in the analysis of the data from earlier experiments. The results of the analyses were as follows.

Text A. Location code difference in the branching network was a significant predictor of the RT data $[F(1,19)=$ $\left.12.76, M S_{\mathrm{e}}=103,409, p<.01\right]$, accounting for $2 \%$ of the variance in these data. None of the other predictors had a statistically significant impact. Location code difference in the branching network was also a significant predictor of the error rate data $\left[F(1,19)=6.75, M S_{\mathrm{e}}=\right.$ $.006, p<.05]$, accounting for $1.5 \%$ of the variance in these data. Again, none of the other predictors had a statistically significant impact.

Text B. Location code difference in the branching network was a significant predictor of the RT data $[F(1,19)=$
9.17. $\left.M S_{\mathrm{e}}=194,655, p<.01\right]$, accounting for $3 \%$ of the variance in these data. None of the other predictors had a statistically significant impact. None of the predictors had a significant impact in the error rate equation.

The results of Experiment 5 offer further evidence in support of the argument overlap hypothesis. SM performance reflected the branching network predicted by this hypothesis rather than the linear network predicted by the causal coherence hypothesis.

\section{EXPERIMENT 6}

An attempt was made in Experiment 6 to obtain analogous evidence with respect to the causal coherence hypothesis. The causal coherence and argument overlap hypotheses predict branching and linear networks, respectively, for the texts of this experiment. A sample text is presented in Table 9.

In its rationale, the experiment was complementary to Experiment 5: If RT and error rate are concave downward as a function of surface position difference, this implies that the texts are represented in the branching networks predicted by the causal coherence hypothesis. On the other hand, if RT and error rate decrease monotonically with surface position difference, this implies either that the texts are represented in the linear networks predicted by the argument overlap hypothesis or that SM performance reflects surface distance. The rationale for the experiment is summarized in Table 4.

\section{Method}

Subjects. The subjects were 20 students from a class in introductory psychology at George Washington University.

Materials. The stimuli were two texts of the form shown in Table 9. The causal coherence network was verified according to the procedure used in Experiment 4. The probes were constructed in the same way as the probes for Experiment 3.

Procedure. The procedure was the same as for Experiment 2.

\section{Results and Discussion}

For both texts, RT and error rate decreased as a function of surface position difference (see Figure 10). ANOVAs revealed significant surface position difference effects in the RT accessibility indices for both texts. The accessibility index was therefore included as a covariate in the analysis of the RT data for the two texts. The analyses revealed significant effects of surface position difference

\section{Table 9}

Sample Stimulus Text From Experiment 6

(S1) Midway through the afternoon performance of the greatest show on earth, a schoolboy booed the liontamer. (S2) That evening, over dinner, the liontamer exploded at the usher. (S3) The usher complained to the magician. (S4) And the magician appealed to the ringmaster for counseling. (S5) Meanwhile, the ringmaster had informed the owner of the afternoon's incident. (S6) The owner had consulted an expert in marketing research. (S7) The expert had recommended an agent. (S8) The agent had engaged a rock star as the main attraction for the next show.

Note-S1, S2, .. = Sentence 1, Sentence 2, etc. 

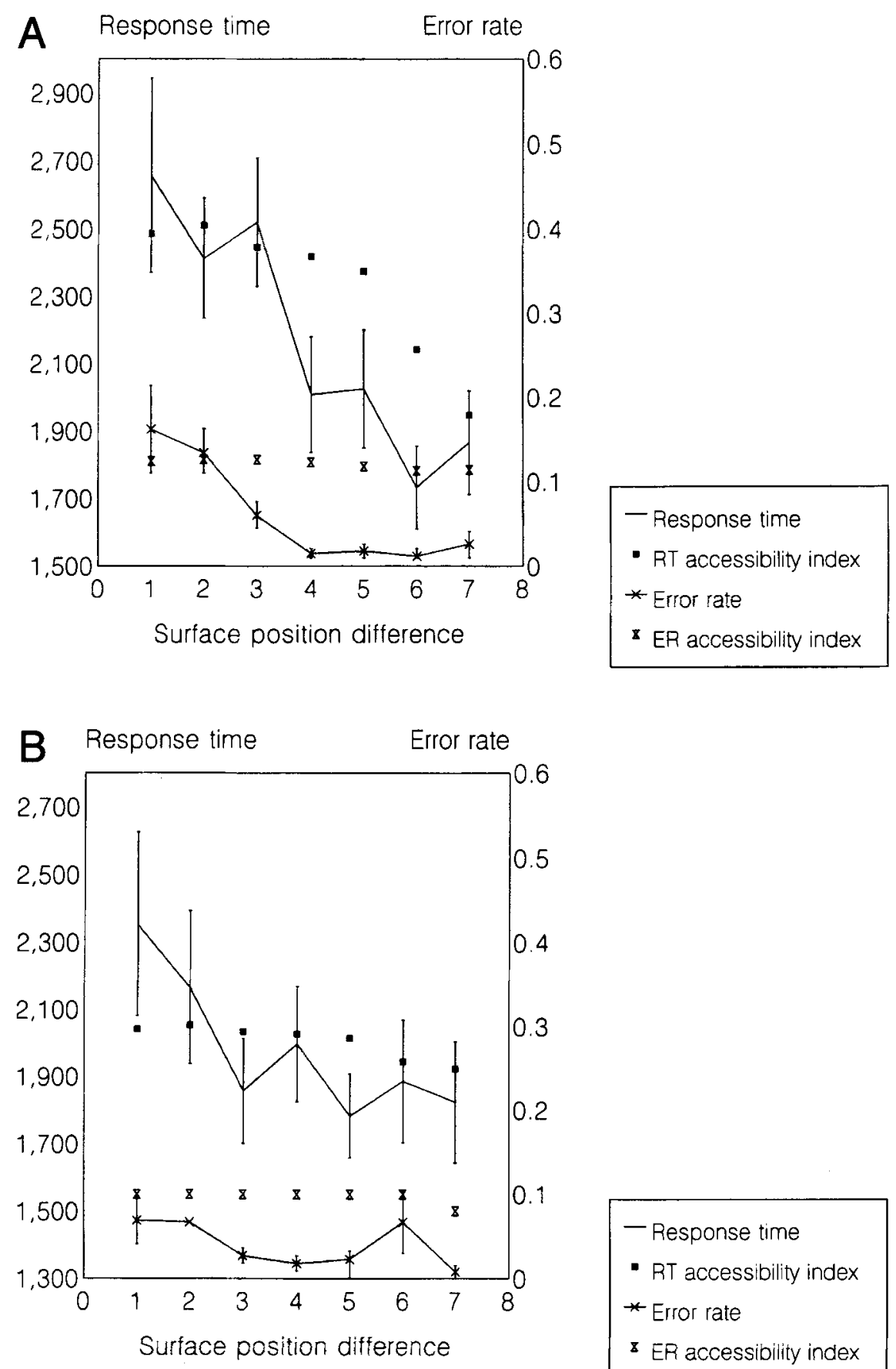

- Response time

- RT accessibility index

* Error rate

ER accessibility index

Figure 10. Experiment 6: Performance on different-branch trials and accessibility indices for Texts $A$ and $B$ as a function of surface position difference.

in the data for Text $\mathrm{A}\left[F(6,113)=11.25, M S_{\mathrm{e}}=222,152\right.$, $p<.0001]$ and Text $\mathrm{B}\left[F(6,113)=3.03, M S_{\mathrm{e}}=288,047\right.$, $p<.05]$. The linear component in the effect for Text $\mathrm{A}$ was significant $\left[F(1,18)=4.77, M S_{\mathrm{e}}=344,727, p<\right.$ $.05]$, but the linear component in the effect for Text B was not significant $\left[F(1,18)=1.52, M S_{\mathrm{e}}=585,382\right.$, $p>.05]$. The quadratic components were not significant in the effects for either text $(F \mathrm{~s}<1)$.
ANOVAs revealed a significant effect of surface position difference in the error rate data for Text $\mathrm{A}[F(6,114)=$ $\left.6.79, M S_{\mathrm{e}}=0.011, p<.005\right]$ and a nearly significant effect in the data for Text B $\left[F(6,114)=2.28, M S_{\mathrm{e}}=\right.$ $0.006, p=.10]$. There were significant linear trends in the data for both texts [Text A, $F(1,19)=13.76, M S_{\mathrm{e}}=$ $0.024, p<.005$; Text B, $F(1,19)=4.65, M S_{\mathrm{e}}=0.005$, $p<.05]$. Although the quadratic component in the effect 
for Text A was significant $\left[F(1,19)=4.65, M S_{\mathrm{e}}=0.022\right.$, $p<.05]$, the pattern was concave upward rather than concave downward. The quadratic component in the effect for Text B was not significant $\left[F(1,19)=2.39, M S_{\mathrm{e}}=\right.$ $0.003, p>.05]$. (In any case, the pattern was concave upward.) The error rate accessibility index did not vary with position difference $(F<1)$.

In order to gather converging support for the results of the surface position analysis, the data for differentbranch trials were also examined with regression analyses. The details of the analyses were the same as for those conducted on the data from Experiment 5.

Text A. Location code difference in the branching network was not a significant predictor of the RT data $\left[F(1,19)=3.00, M S_{\mathrm{e}}=382,402, p>.05\right]$. The surface position variable was a significant predictor of these data $\left[F(1,19)=26.98, M S_{\mathrm{e}}=482,088, p<.001\right]$, accounting for $10 \%$ of the variance in the data. Among the other predictors, only the accessibility variable had a statistically significant impact $\left[F(1,19)=28.31, M S_{\mathrm{e}}=585,549\right.$, $p<.001]$, accounting for $12 \%$ of the variance in the data.

Location code difference in the branching network was a significant predictor of the error rate data $[F(1,19)=$ $\left.9.61, M S_{\mathrm{e}}=0.023, p<.01\right]$; however, the direction of the relationship was the opposite of what was predicted under the location code hypothesis - error rate increased with location code difference. The surface position variable was a significant predictor of the error rate data $[F(1,19)=$ $\left.19.87, M S_{\mathrm{e}}=0.025, p<.05\right]$, accounting for $13 \%$ of the variance in these data. None of the other predictors had a statistically significant impact.

Text B. Location code difference in the branching network was not a significant predictor of the RT data $\left[F(1,19)=1.86, M S_{\mathrm{e}}=244,331, p>.05\right]$. The surface position variable was a significant predictor of these data $\left[F(1,19)=6.18, M S_{\mathrm{e}}=759,813, p<.05\right]$, accounting for $4.3 \%$ of the variance in the data. None of the other predictors had a statistically significant impact.

Location code difference in the branching network was a significant predictor of the error rate data $[F(1,19)=$ 5.03, $\left.M S_{\mathrm{e}}=0.005, p<.05\right]$; however, the direction of the relationship was again the opposite of what was predicted under the location code hypothesis. The surface position variable was a significant predictor of the error rate data $\left[F(1,19)=4.43, M S_{\mathrm{e}}=0.008, p<.05\right]$, accounting for $1.2 \%$ of the variance in these data. None of the control variables had a statistically significant impact.

The experiment produced no evidence that the texts were encoded in the branching network predicted by the causal coherence hypothesis. The results suggest either that the texts were encoded in the linear network predicted by the argument overlap hypothesis or that SM performance reflected surface rather than network distance.

Branching networks predicted by the causal coherence hypothesis were reflected in the data for Experiments 4 and $4 \mathrm{~A}$, but not Experiment 6 . One possibility is that the causal relationships in the texts for Experiment 6 were not as salient as those in the texts for Experiments 4 and
4A. As a test of this possibility, ratings were collected as to the strengths of the causal relationships between the various pairs of the events in question.

One group of 10 subjects rated the event pairs from the causal coherence text for Experiment 4 and one of the texts for Experiment 6 . Another group of 10 subjects rated the pairs from the text for Experiment $4 \mathrm{~A}$ and the other text for Experiment 6 . The subjects assigned a number to each pair of events to indicate how likely it was that the first event caused the second event. The likelihood scale ran from 0 to 10 . The subjects were allowed to take as much time as they wanted in rating the various event pairs. They were allowed to refer to the texts while assigning the ratings.

Table 10 shows the mean likelihood ratings that the subjects produced for the various pairs of events. For all four texts, the strength of the causal relationship between the event pairs decreased with the number of links between the events in the branching network predicted by the causal coherence hypothesis. The texts for Experiment 6 produced generally the same pattern of ratings as those for Experiments 4 and 4A. Most importantly, the strength of the causal relationship between the events described

Table 10

Ratings of the Strengths of the Causal Relationships Between the Pairs of Events Described in the Causal Coherence Texts of Experiments 4, 4A, and 6

\begin{tabular}{|c|c|c|c|c|c|c|c|}
\hline \multirow{2}{*}{$\begin{array}{l}\text { Event } \\
\text { Appearing } \\
\text { First }\end{array}$} & \multicolumn{7}{|c|}{ Event Appearing Second } \\
\hline & 2 & 3 & 4 & 5 & 6 & 7 & 8 \\
\hline \multicolumn{8}{|c|}{ Text From Experiment 4} \\
\hline 1 & 9.7 & 8.9 & 6.6 & 8.2 & 5.1 & 5.7 & 5.6 \\
\hline 2 & & 9.0 & 6.2 & 1.2 & 2.0 & 2.2 & 3.3 \\
\hline 3 & & & 8.8 & 1.0 & 2.2 & 3.8 & 3.5 \\
\hline 4 & & & & 1.2 & 1.1 & 3.0 & 3.4 \\
\hline 5 & & & & & 7.3 & 6.3 & 5.1 \\
\hline 6 & & & & & & 9.0 & 7.0 \\
\hline 7 & & & & & & & 8.1 \\
\hline \multicolumn{8}{|c|}{ Text From Experiment 4A } \\
\hline 1 & 9.9 & 8.1 & 6.5 & 8.1 & 6.0 & 5.5 & 5.6 \\
\hline 2 & & 9.5 & 5.9 & 3.2 & 2.7 & 3.3 & 2.8 \\
\hline 3 & & & 9.4 & 2.6 & 2.0 & 2.0 & 1.8 \\
\hline 4 & & & & 1.1 & 0.6 & 1.8 & 0.8 \\
\hline 5 & & & & & 7.8 & 6.6 & 5.9 \\
\hline 6 & & & & & & 7.7 & 7.2 \\
\hline 7 & & & & & & & 8.9 \\
\hline \multicolumn{8}{|c|}{ Text A From Experiment 6} \\
\hline 1 & 8.2 & 4.6 & 3.3 & 8.6 & 6.1 & 3.8 & 8.3 \\
\hline 2 & & 9.3 & 4.8 & 3.9 & 2.2 & 0.5 & 2.8 \\
\hline 3 & & & 7.9 & 3.2 & 0.8 & 1.2 & 0.7 \\
\hline 4 & & & & 1.0 & 1.0 & 1.5 & 1.2 \\
\hline 5 & & & & & 9.3 & 5.1 & 7.0 \\
\hline 6 & & & & & & 9.1 & 8.1 \\
\hline 7 & & & & & & & 9.5 \\
\hline \multicolumn{8}{|c|}{ Text B From Experiment 6} \\
\hline 1 & 9.8 & 4.8 & 6.1 & 8.1 & 6.2 & 6.6 & 5.4 \\
\hline 2 & & 7.3 & 8.1 & 1.7 & 1.3 & 1.3 & 1.6 \\
\hline 3 & & & 9.7 & 0.3 & 0.2 & 0.7 & 0.7 \\
\hline 4 & & & & 1.9 & 0.0 & 1.0 & 0.0 \\
\hline 5 & & & & & 7.7 & 6.5 & 5.1 \\
\hline 6 & & & & & & 9.3 & 7.6 \\
\hline 7 & & & & & & & 8.6 \\
\hline
\end{tabular}


in Sentences 1 and 5 was as strong in the texts for Experiment 6 as in the texts for the earlier experiments. This relationship was crucial to the branching structure of the network that the causal coherence hypothesis predicted.

The results of the follow-up study imply that the causal relationships in the texts for Experiment 6 were as salient as the ones in the texts for Experiments 4 and 4A. However, whereas the branching networks predicted for the texts for Experiments 4 and $4 \mathrm{~A}$ were reflected in SM performance, those predicted for the texts for Experiment 6 were not. It seems, then, that when the principle of argument overlap is absent as an integrative factor in a text, and the causal coherence hypothesis predicts a branching network, that network is reflected in SM performance. When the principle of argument overlap is present, however, the branching network predicted by the causal coherence hypothesis is not reflected in SM performance. The implications of this will be considered in the General Discussion section.

\section{EXPERIMENT 7}

The texts of Experiments 5 and 6 were reasonably artificial and were learned to a strict criterion. To increase the generality of the findings of those experiments, an attempt was made in Experiments 7 and 8 to replicate them using more elaborate texts and a procedure in which subjects merely read the stimulus texts.

\section{Method}

Subjects. The subjects were 20 students from a class in introductory psychology at George Washington University.
Table 11

\section{Sample Stimulus Text From Experiment 7}

The mayor was fed up with the corruption that surrounded him. (S1) He unleashed the detective, with orders to clean up the town. As his first assignment of the day, (S2) the detective tailed the pimp. At the corner of Broadway and Fifty-second, (S3) the pimp met the showgirl. Hearty greetings were exchanged. (S4) Then the showgirl introduced her companion, the governor. The next day, (S5) the mayor encouraged the district attorney to produce similar results. On a hunch, (S6) the district attorney bugged the banker. Tension was high at the secret listening post. That afternoon, (S7) the banker phoned the senator. During the course of the conversation, (S8) the senator praised the mobster.

Note--S1, S2, . = Sentence 1, Sentence 2, etc.

Materials. The six stimulus texts resembled the texts of Experiment 5 in their basic structural skeletons. They differed from those texts in that they were more highly elaborated. Specifically, more qualifying phrases and clauses and more background and scene-setting sentences were included. A sample text is presented in Table 11 .

There were 16 different-branch probes for each text. They were constructed by (1) forming the 16 possible unordered pairs of the four key clauses in the two branches of the basic structural skeleton of the text (these clauses are italicized in the sample text shown in Table 11) and (2) choosing a content word at random from each of the clauses in each pair. For the Clause Pair 1-5, words that were repeated in the two clauses were not used.

There were six same-branch probes for each text. They were constructed by (1) forming all possible unordered pairs of the clauses that were adjacent in the structural skeleton and (2) choosing a content word at random from each of the clauses in each pair.

There were 16 positive probes for each text. They were constructed by (1) forming, for each of the eight key clauses, the three unordered pairs that could be formed of the three content words in the clause and (2) randomly choosing two of the three word pairs for presentation.

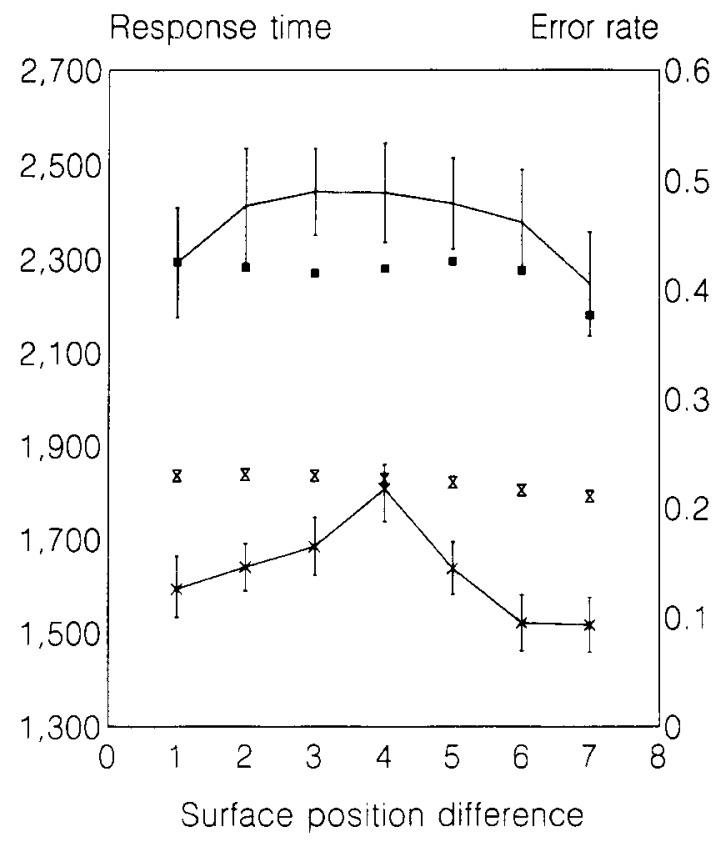

$$
\begin{aligned}
& \text { - Response time } \\
& \text { - RT accessibility index } \\
& \text { * Error rate } \\
& \text { × ER accessibility index }
\end{aligned}
$$

Figure 11. Experiment 7: Performance on different-branch trials and accessibility indices as a function of surface position difference. 
Procedure. The subject read the texts on a computer monitor Each text was displayed in its entirety for as long as the subject wanted. After reading each text, the subject was asked two recall questions concerning the text (e.g., What did the detective do?). The subject was then presented with a series of 38 word-pair probes concerning the text. The rest of the procedure was the same as that of Experiment 3.

\section{Results}

$\mathrm{RT}$ and error rate for different-branch trials were concave downward as a function of surface position difference (see Figure 11). Although the effect of surface position difference in the RT data was not significant [subjects, $F(6,114)=1.62, M S_{\mathrm{e}}=72,983, p>.05$; items, $F(6,30)=$ $0.359]$, the effect in the error rate data was significant [subjects, $F(6,114)=4.70, M S_{\mathrm{e}}=0.008, p<.005$; items, $\left.F(6,30)=3.40, M S_{\mathrm{e}}=0.004, p<.05\right]$, as was the quadratic component of this effect [subjects, $F(1,19)=6.81$, $M S_{\mathrm{e}}=0.017, p<.05$; items, $F(1,5)=10.02, M S_{\mathrm{e}}=0.005$, $p<.05]$.

The error rate accessibility index did not vary significantily as a function of surface position difference [subjects, $F(6,114)=1.779, M S_{\mathrm{e}}=0.001, p>.05$; items, $F(6,30)<1]$. More to the point, the index did not show a significant quadratic trend [subjects, $F(1,19)=2.21$, $M S_{\mathrm{e}}=0.001, p>.05$; items, $\left.F(1,5)<1\right]$. The concavedownward effect in the error rate data supports the predictions of the argument overlap hypothesis.

In order to gather further support for this hypothesis, the data were examined with regression analyses. The details of the analyses were the same as for those conducted on the data from Experiment 5. Location code difference in the branching network was a significant predictor of the RT data $\left[F(1,19)=6.21, M S_{\mathrm{e}}=112,316, p<.05\right]$, accounting for $1.5 \%$ of the variance in these data. None of the other variables had a significant impact.

Location code difference in the branching network was a significant predictor of the error rate data $[F(1,19)=$ $\left.41.22, M S_{\mathrm{e}}=0.01, p<.001\right]$, accounting for $8 \%$ of the variance in these data. Among the other predictor variables, only the surface position variable had a statistically significant impact $\left[F(1,19)=5.9, M S_{\mathrm{e}}=0.01, p<\right.$ $.05]$, accounting for $1.1 \%$ of the variance in the data.

\section{EXPERIMENT 8}

\section{Method}

The subjects were 8 students from a class in introductory psychology at George Washington University. The eight stimulus texts resembled the texts of Experiment 6 in their basic structural skeletons. They differed from those texts in that they were more highly elaborated. The procedure was identical to that of Experiment 7.

\section{Results}

RT and error rate for different-branch trials decreased monotonically as a function of surface position difference (see Figure 12). The effect of surface position difference in the RT data was statistically significant [subjects, $F(6,42)=2.71, M S_{\mathrm{e}}=44,098, p=.08$; items, $F(6,42)=$ $\left.2.90, M S_{\mathrm{e}}=32,417, p<.05\right]$, as was the linear component of this effect [subjects, $F(1,7)=9.64, M S_{\mathrm{e}}=57,573$, $p<.05$; items, $\left.F(1,7)=16.10, M S_{\mathrm{e}}=29,314, p<.01\right]$. The quadratic component was not significant $(F \mathrm{~s}<1)$. The effect of surface position difference in the error rate data was significant against the variability due to subjects $\left[F(6,42)=3.97, M S_{\mathrm{e}}=0.007, p<.05\right]$, but not

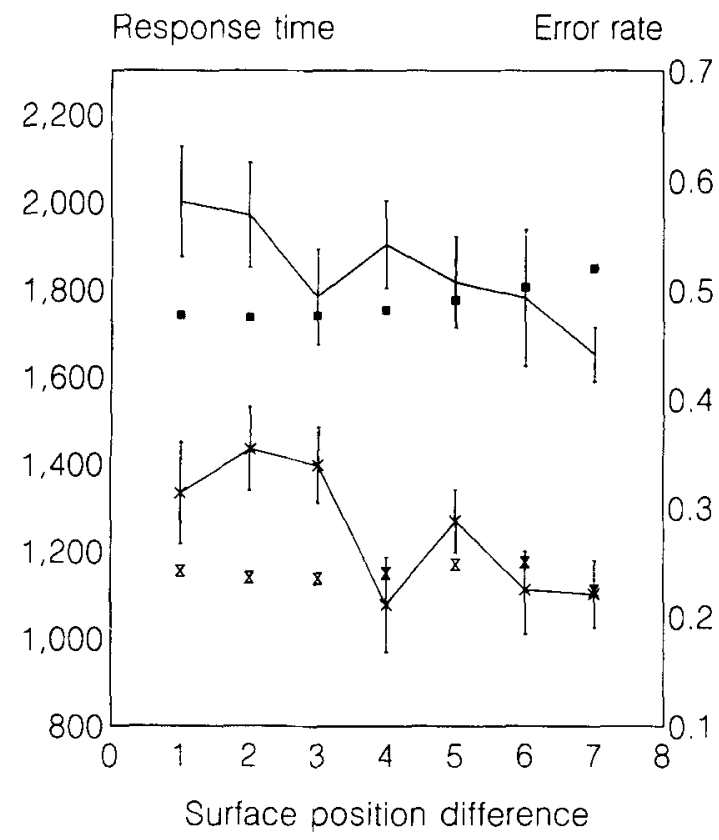

$$
\begin{aligned}
& \text { - Response time } \\
& \text { - RT accessibility index } \\
& \text { * Error rate } \\
& \text { × ER accessibility index }
\end{aligned}
$$

Figure 12. Experiment 8: Performance on different-branch trials and accessibility indices as a function of surface position difference. 
against the variability due to items $[F(6,42)=1.004$, $\left.M S_{\mathrm{e}}=0.03, p>.05\right]$. There was a significant linear trend in the subjects effect $\left[F(1,7)=10.94, M S_{\mathrm{e}}=\right.$ $0.009, p<.05]$, and the quadratic trend was not significant $[F(1,7)<1]$.

The RT accessibility index increased as a function of surface position difference, and the error rate index did not vary as a function of surface position difference $\left(F_{\mathrm{s}}<1\right)$. The effect in the data for different-branch trials cannot therefore be attributed to a pattern of differential accessibility.

The decreasing linear pattern that was observed in the surface position difference analysis replicates the pattern observed in Experiment 6. There was again no evidence that the texts were encoded in terms of the branching network predicted by the causal coherence hypothesis.

In order to gather further evidence that this was the case, the data were again examined with regression analyses. The details of the analyses were the same as for those conducted on the data from Experiment 5. Location code difference in the branching network was not a significant predictor of the $\mathrm{RT}$ data $[F(1,7)<1]$. The surface position variable was an almost significant predictor of the RT data $\left[F(1,7)=3.72, M S_{\mathrm{e}}=79,600, p>.05\right]$. None of the other predictor variables had a significant impact.

Location code difference in the branching network was not a significant predictor of the error rate data $[F(1,7)=$ $\left.2.87, M S_{e}=0.009, p>.05\right]$. The surface position variable was a significant predictor of the error rate data $\left[F(1,7)=21.11, M S_{\mathrm{e}}=0.01, p<.001\right]$, accounting for $8 \%$ of the variance in these data.

\section{Discussion of Experiments 7 and 8}

The basic data pattern of Experiments 5 and 6 was replicated in Experiments 7 and 8. The major difference between the outcomes of the two sets of experiments was that the predictions of the argument overlap hypothesis were supported only in the error rate data for Experiment 7 . The predictions of this hypothesis were supported, however, in the regression analyses of both the RT and the error rate data for that experiment.

\section{GENERAL DISCUSSION}

Experiments 4, 4A, 5, and 7 provided evidence that texts are represented in memory according to the dictates of the argument overlap hypothesis; Experiments 4 and $4 \mathrm{~A}$ provided evidence that texts are represented in memory according to the dictates of the causal coherence hypothesis. In general, these results augment the evidence that has been obtained for the argument overlap and causal coherence hypotheses with other methods.

Over the course of the study, more evidence was produced for the argument overlap hypothesis than for the causal coherence hypothesis. When either hypothesis was the sole integrative factor in a text, its predictions were supported. When both hypotheses were present as integrative factors, the predictions of the argument overlap hypothesis were supported.
What can we make of this disparity? It would certainly be wrong to conclude that the argument overlap hypothesis is more important than the causal coherence hypothesis in understanding the organization of narrative text in memory. First, there is no guarantee that the relationships of argument overlap and causal coherence were equally salient to the subjects of the study. Second, the SM task may not be equally sensitive to all levels of representation in text memory records.

The disparity does suggest a more limited conclusion, however, that may be of some interest: The argument overlap hypothesis is more influential than the causal coherence hypothesis in predicting SM distance effects. This conclusion can be justified as follows: The rating data reported in the Discussion section of Experiment 6 imply that the causal relationships in the texts of Experiment 6 were as strong, in the perception of the subjects, as those in the texts of Experiments 4 and 4A. Unlike the causal relationships for the texts of Experiments 4 and $4 \mathrm{~A}$, those for the texts of Experiment 6 were not reflected in SM distance effects. The primary difference between the two sets of texts was that argument overlap was present as an integrative factor in the texts of Experiment 6 but not in the texts of Experiments 4 and 4A. This suggests that the network links predicted by the causal coherence hypothesis in Experiment 6 were overshadowed, with respect to the determination of SM distance effects, by network links predicted by the argument overlap hypothesis.

An overshadowing of this kind can perhaps be reconciled with the text representation literature. One, admittedly speculative, possibility is that relationships of causal coherence are recorded at a more abstract level of representation than are relationships of argument overlap, and that the SM task is primarily sensitive to the level of representation at which argument overlap relationships are recorded.

There is some support for this idea in the text processing literature. Most writers hold that relationships of argument overlap are recorded at the propositional level of representation (Anderson, 1983; Kintsch \& van Dijk, 1978). There is more disagreement concerning the level of representation at which relationships of causal coherence are recorded. Graesser (1981) holds that such relationships are recorded at the propositional level of representation. On the other hand, Trabasso and his colleagues (Trabasso \& Sperry, 1985; Trabasso \& van den Broek, 1985 ) hold that such relationships are recorded at a more abstract level, at which the text is decomposed in terms of events. (Note that the texts of the present study broke down, for the most part, into the same units at the sentence, event, and proposition level.)

In the advantage that they reveal for relationships of argument overlap, the present results are consistent with the view of Trabasso and his colleagues concerning the level of representation at which causal links are recorded (in this connection, see also Fletcher \& Chrysler, 1990). If the suggested interpretation of these results is correct, it should be possible to come up with a task that would be primarily sensitive to the level of representation at 
which causal coherence links are recorded and in which argument overlap links would be overshadowed by causal coherence links.

Of course, interpretation of the present results must be qualified by the fact that the stimulus texts for the early experiments in the study were rather list-like and artificial. The observation of similar findings with more naturalistic materials would certainly be useful. It should be noted, however, that the results of the early experiments were replicated in Experiments 7 and 8 with texts that were, if not more naturalistic, at least more highly elaborated. Furthermore, even though the list-like properties of the texts for the early experiments may have helped to increase the strength of the distance effects that were obtained, these distance effects reflected branching network structures and not simple list structures.

In summary, the present results provide evidence that texts are represented in memory according to the dictates of both the argument overlap and the causal coherence hypothesis. Furthermore, these results suggest that causal relationships are recorded at a different, more abstract level of representation than are argument relationships.

In all of the present experiments, the evidence took the form of distance effects in a memory retrieval task. The SM methodology may usefully complement the priming methodology as a means of producing distance effects that reflect network representations. In fact, the priming methodology may not be particularly effective for producing such results. According to the retrieval theory of priming, variation in the degree of priming between pairs of words from a text reflects variation in the degree to which the words share the same retrieval cues (Ratcliff \& McKoon, 1988). This, in turn, reflects the degree to which the words (or the propositions/sentences to which they belong) were processed together during the comprehension of the text.

Given these constraints, it is difficult to see how priming data can accurately reflect the distance relationships in network structures. Consider a branching network such as is shown in Figure 6. It is difficult to see how the retrieval theory could predict priming effects that would reflect all of the distance relationships in this network. The theory could predict more priming between $\mathrm{S} 1$ and S2 than between S1 and S3; S2 would be more likely to be processed together with $S 1$ than would S3. The theory could also predict more priming between $\mathrm{S} 1$ and $\mathrm{S} 5$ than between S1 and S4; S1 would be reinstated during the processing of S5 but not during the processing of S4. It is not clear, however, that the theory would predict more priming between S2 and S5 than between S3 and S5. S2 would be less likely to be processed together with S5 than would S3. And S2 would be no more likely to be reinstated during the processing of S5 than would S3.

The distance effects that are observed in the SM task are related to distance effects that have been observed in several other areas of cognitive psychology. The resemblance to the symbolic distance effect was noted earlier (Banks, 1977; Moyer \& Bayer, 1976). The SM distance effect also has some resemblance to the semantic dis- tance effect, which occurs in category verification tasks (Smith, 1978). Here, it is found that subjects can verify a category membership statement more quickly as being true the more closely its subject and predicate are related, and they can identify a statement more quickly as being false the less closely its subject and predicate are related.

The location code hypothesis, which was supported in the present experiments as an explanation of the SM distance effect, is more closely related to explanations of the symbolic distance effect than the semantic distance effect. The key point of similarity is that both explanations posit the comparison of information that explicitly locates the test items in a comparison "space" of some sort. In the case of the symbolic distance effect, this space is given by the dimension along which the test items are being compared. In the case of the SM distance effect, the space does not have a clearly articulated dimensional structure. It is simply the space in which the network representation for a text is situated.

The SM distance effect may be useful in studies of text representation. This is especially true given that the priming methodology may not be completely effective as a means of detecting distance effects that are determined by network structures. From the fact that the location code hypothesis was supported in the present study, we may form an idea of the kinds of questions that SM data would be useful in answering. These results imply that SM data may be useful for forming inferences about the broad scale configuration of idea units in text memory records but may be less useful for deciding whether or not particular network links are present in text memory records. As long as the presence or absence of a link does not dictate a significant change in the configuration of idea units that is given by surface form, its presence or absence will not be reflected in SM data.

From the fact that the location code hypothesis was supported, we may also be able to gain some insight into the process by which network representations are constructed in memory. According to this hypothesis, a code is stored with each proposition/sentence of a text that indicates its position in the text's network representation. We can infer from this that network representations are constructed by a reasonably high-level process. This process does not merely form pairwise linkages between idea units. Rather, it is sensitive to the overall configuration of the network that is being formed. If two idea units hold analogous positions in different parts of the network (e.g., if two units hold the same branch position), they are encoded as doing so.

\section{REFERENCES}

ANDERSON, J. R. (1976). Language, memory, and thought. Hillsdale, NJ: Erlbaum.

ANDERSON, J. R. (1983). The architecture of cognition. Cambridge, MA: Harvard University Press.

BANKs, W. P. (1977). Encoding and processing of symbolic information in comparative judgements. In G. H. Bower (Ed.), The psychology of learning and motivation (Vol. 11, pp. 101-159). New York: Academic Press.

Bloom, C. P., Fletcher, C. R., van den Broek, P., Rejtz, L., \& 
SHAPIRO, B. P. (1990). An on-line assessment of causal reasoning during comprehension. Memory \& Cognition, 18, 65-71.

Dell, G. S., MCKoon, G., \& RatclifF, R. (1983). The activation of antecedent information during the processing of anaphoric reference in reading. Journal of Verbal Learning \& Verbal Behavior, 22, 121 . 132.

Dopkins, S., Klin, C., \& Myers, J. L. (1993). Accessibility of information about goals during the processing of narrative texts. Journal of Experimental Psychology: Learning, Memory, \& Cognition, $19,70-80$.

FletCher, C. R., \& Bloom, C. P. (1988). Causal reasoning in the comprehension of simple narrative texts. Journal of Memory \& Language, 27, 235-244.

Fletcher, C. R., \& Chrysler, S. T. (1990). Surface forms, textbases, and situation models: Recognition memory for three types of textual information. Discourse Processes, 13, 175-190.

Graesser, A. C. (1981). Prose comprehension beyond the word. New York: Springer-Verlag.

KERST, S. M,, \& HoWARD, J. H., JR. (1977). Mental comparisons for ordered information on abstract and concrete dimensions. Memory \& Cognition, 5, 227-234.

KinTSCH, W., \& VAN DiJK, T. (1978). Toward a model of text comprehension and production. Psychological Review, 85, 363-394.

LORCH, R. F., \& MYERS, J. L. (1990). Regression analyses of repeated measures data in cognitive research. Journal of Experimental Psychology: Learning, Memory, \& Cognition, 16, 149-157.

Magliano, J. P., Bagget, W. B., Johnson, B. K., \& Graesser, A. C. (1993). The time course of generating causal antecedent and causal consequence inferences. Discourse Processes, 16, 35-53.

McKoon, G., \& RatCliff, R. (1980). Priming in item recognition: The organization of propositions in memory for text. Journal of Verbal Learning \& Verbal Behavior, 19, 369-386.

MOYer, R. S., \& BAYER, R. H. (1976). Mental comparison and the symbolic distance effect. Cognitive Psychology, 8, 228-246.

O'BRIEN, E. J., DUfFy, S. A., \& MYERS, J. L. (1986). Anaphoric inference during reading. Journal of Experimental Psychology: Learning, Memory, \& Cognition, 12, 346-352.

O'BRIEN, E. J., \& MYERS, J. L. (1987). The role of causal connections in the retrieval of text. Memory \& Cognition, 15, 419-427.

RatCliff, R., \& McKoon, G. (1988). A retrieval theory of priming in memory. Psychological Review, 95, 385-408.

Sмiтh, E. E. (1978). Theories of semantic memory. In W. K. Estes (Ed.), Handbook of learning and cognitive processes (Vol. 6, pp. 156). Hillsdale, NJ: Erlbaum.

Trabasso, T., \& SPERRY, L. L. (1985). Causal relatedness and importance of story events. Journal of Memory \& Language, 24, 595-611.

Trabasso, T., \& SuH, S. (1993). Understanding text: Achieving explanatory coherence through on-line inferences and mental operations in working memory. Discourse Processes, 16, 3-34.

Trabasso, T., \& van Den Broek, P. (1985). Causal thinking and the representation of narrative events. Journal of Memory \& Language, 24, 612-630.

VAN DEN BRoEk, P. W., \& LORCH, R. F. (1993). Network representations of causal relations in memory for narrative texts: Evidence from primed recognition. Discourse Processes, 16, 75-98.

VAN DiJK, T., \& KinTSCH, W. (1983). Strategies of discourse comprehension. New York: Academic Press.

(Manuscript received February 25, 1994; revision accepted for publication October 18,1995 .) 